\title{
Article \\ Spatial Heterogeneity of Carbon Emissions and Its Influencing Factors in China: Evidence from 286 Prefecture-Level Cities
}

\author{
Chen $\mathrm{Li}^{1}$, Heng $\mathrm{Li}^{2}$ and Xionghe Qin ${ }^{3, *}$ \\ 1 School of Management, Shanghai University of Engineering Science, Shanghai 201620, China; \\ 22150003@sues.edu.cn \\ 2 School of Economic and Management, Huainan Normal University, Huainan 232038, China; \\ liheng968@163.com \\ 3 School of Urban and Regional Science, East China Normal University, Shanghai 200062, China \\ * Correspondence: xhqin@re.ecnu.edu.cn
}

check for updates

Citation: Li, C.; Li, H.; Qin, X. Spatial Heterogeneity of Carbon Emissions and Its Influencing Factors in China: Evidence from 286 Prefecture-Level Cities. Int. J. Environ. Res. Public Health 2022, 19, 1226. https:// doi.org/10.3390/ijerph19031226

Academic Editor: Paul B. Tchounwou

Received: 15 December 2021

Accepted: 20 January 2022

Published: 22 January 2022

Publisher's Note: MDPI stays neutral with regard to jurisdictional claims in published maps and institutional affiliations.

Copyright: (C) 2022 by the authors. Licensee MDPI, Basel, Switzerland. This article is an open access article distributed under the terms and conditions of the Creative Commons Attribution (CC BY) license (https:// creativecommons.org/licenses/by/ $4.0 /$ )

\begin{abstract}
In the face of the severe challenge of global warming, promoting low-carbon emission reductions is an important measure to cope with global climate change and achieve a green cycle of sustainable development. The purpose of this study was to reveal the spatial heterogeneity of carbon emissions and the influencing factors in 286 prefecture-level-and-above cities in China, and to provide an empirical basis for the formulation of low-carbon emission reduction policies in China. This study used a combination of comparative analysis, regional difference analysis, correlation analysis, principal component analysis, and stepwise regression analysis to analyze the spatial differences in carbon emissions and their influencing factors in 286 prefecture-level-and-above cities in China, and draws the following main conclusions: (1) From 2005 to 2015, regional differences in six sectors, including household carbon emissions, widened in the 286 prefecture-level-and-above cities in China, while regional differences in 14 sectors, including rural household carbon emissions, narrowed. (2) There were significant intra-group differences in urban household carbon emissions, and the contributions to intra-group differences in carbon emissions differed across the six sectors in the northeast, east, central, and west regions. (3) Although the total and average carbon emissions of each sector increased from 2005 to 2015, China's carbon emission intensity was decreasing, and carbon productivity is increasing. (4) Carbon emissions per capita (CCE) were positively correlated with GRP per capita, industrial $\mathrm{SO}_{2}$ emissions per capita, and the proportion of employees in the secondary sector, and negatively correlated with population density and the proportion of employees in the tertiary sector. (5) Resident savings and consumption factors, pollution emission factors, and economic structure factors had a facilitating effect on CCE, while population density factors and economic growth factors have a weakening effect on CCE.
\end{abstract}

Keywords: carbon emissions; spatial heterogeneity; Theil index; 286 prefecture-level cities; China

\section{Introduction}

Global warming has become a serious challenge that threatens the survival and sustainable development of mankind, and promoting low-carbon emission reductions is an important step in addressing global climate change and achieving green cycle sustainable development [1-3]. However, China has a long way to go in terms of low carbon emission reductions. The increase in carbon emissions mainly comes from the expansion of the economy [4-7], which in turn further stimulates the consumption of energy and the continuous growth of carbon emissions [8-10]. The China Urban Greenhouse Gas Emissions Dataset (2015) shows that Beijing and Shanghai, the two largest cities in China, have per capita carbon emissions of 7.33 tonnes per person and 11.46 tonnes per person, respectively, while Copenhagen, Paris, New York, Tokyo, and London have per capita carbon emissions of 2.87 tonnes per person, 3.50 tonnes per person, 7.96 tonnes per person, 4.97 tonnes per person, and 5.03 tonnes/capita. The two most-developed mega-cities in China have higher 
per capita carbon emissions than most world-renowned cities [11]. There are also significant regional differences in the intensity of carbon emissions, due to the different stages and regional economic development levels in China. Therefore, strengthening research on the spatial heterogeneity of carbon emissions in Chinese cities, measuring regional variations in carbon emissions by sector, and accurately portraying the spatial heterogeneity of carbon emissions, in terms of spatial and temporal evolution patterns and their influencing factors, are of reference value in promoting the coordinating the low-carbon development of China and improving the scientific and targeted nature of energy conservation and emission reduction policies.

Based on the above background, the study of carbon emissions has rapidly become a hot topic in academic circles, and scholars have conducted research on measurement methods, influencing factors, and the spatial heterogeneity of carbon emissions, among which the spatial heterogeneity of carbon emissions, as an important element of low-carbon emission reductions, is one of the key concerns of scholars.

(1) In terms of research topics, Wang, Su, and Zhao quantitatively identified the evolutionary pathways of urban carbon emissions in China [12]. Li, Ma, and Wei explored the characteristics and variability of energy carbon emission efficiency in different regions in China [13]. Qiu and Xu conducted an empirical study on the spatial and temporal differences in carbon emissions of 13 representative cities in eight urban agglomerations in China [14]. Wang et al. used a super-efficient SBM model to measure urban carbon emission performance [15]. Wu analyzed the time-series evolution and spatial variation of carbon emissions across cities in Guangdong province [16]. Xu studied the per capita carbon emissions in Jiangsu Province from 2003 to 2018 [17]. Regarding the analysis of spatial heterogeneity of sectorial carbon emissions, scholars have measured and analyzed the spatial heterogeneity of carbon emissions from the agriculture sector [18-20], services sector [21], manufacturing sector [22], transportation sector [23,24], and food consumption sector [25] in Chinese cities, respectively. Most of the existing studies analyzed the spatial heterogeneity of national, regional, and, especially, sectorial carbon emissions, failing to combine the three and, thus, lacking in relativity and comprehensiveness. At present, most studies are limited by the availability of data and focus on the spatial heterogeneity of carbon emissions at large scales, such as national, regional, and provincial scales, while most studies at the city scale focus on the time series analysis of carbon emissions of individual cities, especially those with more complete data for municipalities directly under the central government, but they rarely involve regional differences in the spatial heterogeneity of urban carbon emissions at the national level. In general, the existing literature on the spatial heterogeneity of carbon emissions mainly focuses on the provincial spatial scale, while there are few studies at an urban scale.

(2) In terms of research methods, the main methods for measuring carbon emissions are the emission factor method, input-output method, life-cycle method, material balance method, actual measurement method, and modeling method. Specifically, Schipper used the factor decomposition method to analyze the carbon emission intensity of 13 IEA countries [26]. Casler used the modeling method to structurally analyze carbon emissions in the US [27]. Chang et al. studied Taiwan's industrial carbon emissions and their structural decomposition based on the input-output method [28]. Guo used a structural decomposition analysis on the basis of the input-output method to decompose the growth of carbon dioxide in China [29]. Scholars have also used the Theil index, Dagum Gini coefficient, and other methods to measure variables such as total carbon emissions and carbon emission efficiency, in order to examine the spatial heterogeneity of carbon emissions in China [30-34]. On this basis, some studies used spatial analysis methods such as Moran's I index and generalized spatial model, to reveal the spatial effects of carbon emissions in China [35-37]. The above studies focused on the influence of industrial structure on carbon emissions, but did not consider the intensity of carbon emissions and their heterogeneity in different sectors and regions. 
(3) In terms of research data, given the availability of data, scholars mostly use the technical classification method recommended by the IPCC to estimate carbon emissions, and most Chinese scholars account for carbon emissions based on officially published energy consumption statistics. Although they used night scene lighting data to estimate carbon emissions across the country, and compared the spatial heterogeneity of carbon emissions in different spatial units, such as regions, provinces, and cities [38-42], their data are still based on experimental estimation, and the accuracy of this estimation needs to be improved. Due to the differences in the caliber of energy statistics among provinces, it is complicated to perform carbon emission accounting, resulting in a lack of research on the heterogeneity of urban carbon emissions and influencing factors based on the national level. Although scholars have conducted spatio-temporal simulations of carbon emissions in Chinese cities, based on satellite nighttime lighting data $[43,44]$, and used urban remote sensing simulations to invert carbon emissions data and conduct evolutionary simulation analyses of carbon emissions in Chinese cities, studies on the spatial heterogeneity of carbon emissions at the city scale have mainly used simulated data, and their data accuracy needs to be improved.

(4) In terms of influencing factors, researchers have explored the influencing factors of carbon emissions using the IPAT model and its extension STIRPAT model, Kaya's constant equation, and the LMDI exponential decomposition method [45-47]. Padilla analyzed the impact of national income differences on $\mathrm{CO}_{2}$ emission differences [48]. Sather used the coefficient of variation, Gini coefficient, and Theil index to measure the spatial differences in $\mathrm{CO}_{2}$ emissions between the eastern, central, and western regions of China [49]. Shao used the Tapio decoupling model to analyze the impact of economic growth patterns on regional carbon emissions in six central provinces of China [50-52]. Although research has initially been specific to the issue of factors influencing the spatial heterogeneity of carbon emissions, extensive studies have been conducted in the academic community, but no consistent conclusions have been reached, and the analysis of the factors influencing spatial heterogeneity still needs to be further explored.

In summary, many scholars have analyzed the spatial heterogeneity of carbon emissions in China at national, regional, and provincial spatial scales, and have achieved rich results. However, due to data limitations, these studies are mainly based on provincial data, and few scholars have examined the spatial heterogeneity of carbon emissions in China using city unit data. In fact, the spatial heterogeneity of carbon emissions across different urban units is even more pronounced, and the study of urban data is crucial for capturing regional heterogeneity and formulating reasonable and effective carbon emission reduction policies. Although some scholars have measured carbon emissions in typical cities based on carbon emission data, their studies were limited to smaller spatial areas and could not grasp the overall pattern of carbon emissions in China from a comprehensive and overall perspective.

Unlike previous studies, this study adopted the Theil index, principal component analysis, and stepwise regression analysis models to comprehensively examine the spatial heterogeneity of carbon emissions in China and its influencing factors, based on carbon emission data from 286 cities at the prefectural level and above in China. The contributions of this paper are mainly reflected in: first, in terms of sample data, the data of the Chinese urban greenhouse gas emission dataset were used in this paper, which draws on the collective wisdom of 137 scientists in China, and lays a solid research foundation for a comprehensive examination of the spatial heterogeneity of carbon emissions in China; second, in terms of spatial scale, the Theil index was used to decompose the eastern region, the central region, the western region, and the northeastern region, at the spatial scale. Finally, the Theil index was used to decompose the structure of the intrinsic differences in carbon emissions of 20 sectors in the cities of four regions, including the eastern, central, western, and northeastern regions, and to compare the intra-group and inter-group differences in carbon emissions of each sector. This study will provide a scientific basis for the formulation of the 'Carbon Summit' action plan for 2030. 
Our research objects were 286 cities in four regions of eastern, western, central, and northeastern China. There are significant spatial differences in regional features, such as the population density, economic activity, and weather conditions among the four regions. The spatial difference of regional economic development level presents a significant stepby-step distribution characteristic. The economic development level decreased from coastal areas to inland areas, with the highest in the eastern region, the second in the central region, and the lowest in the west and northeast regions. The geographical distribution of China's urban population is uneven, with a densely populated eastern area and sparsely populated western area. This spatial distribution pattern is separated by the 'Hu Huanyong Line', an imaginary line that divides China into two parts with roughly equal populations, from Heihe (a northern Chinese city bordering Russia) to Tengchong (a southwestern city bordering China with Myanmar) [53,54]. During the study period, the overall migration of China's population mainly flowed from the northeast and west regions to the central and eastern regions. In terms of the weather conditions, the southeastern areas at low latitudes have higher temperatures and more precipitation throughout the year, while the northwestern areas are hot and rainy in summer, and cold and dry in winter. The spatial differences of these factors may be somewhat related to the spatial heterogeneity of carbon emissions in China.

The purpose of this study was to reveal the spatial and temporal differences between sectors in China and to identify the main drivers of carbon emissions in China. The organizational framework of this paper is as follows: Part I is an introduction; Part II is an introduction to the methodology and data sources; Part III is an analysis of regional differences and a comparative analysis of carbon emissions by sector; Part IV is a correlation analysis, principal component analysis and stepwise regression analysis of the factors influencing carbon emissions in 286 prefecture-level-and-above cities in China; Part V has a discussion; Part VI get conclusions; and Part VII has policy recommendations.

\section{Methods}

2.1. Research Methods

\subsubsection{Spatial Heterogeneity Analysis}

The Theil index examines inequality and disparity from the concepts of information quantity and entropy, and it decomposes overall disparity into disparity between parts and disparity within parts, which has wide applications for analyzing and decomposing disparity and inequality [55-57].The composite entropy index examines the variability among individuals from the concepts of information quantity and entropy, which is the expected value of information quantity, i.e., the expected information quantity [58,59]. The closer the individuals are to each other, the smaller the composite entropy index will be.

$$
G E=\left\{\begin{array}{l}
\sum_{i=1}^{n} p_{i}\left[\left(y_{i} / u\right)^{c}-1\right], c \neq 0,1 \\
\sum_{i=1}^{n} p_{i}\left(y_{i} / u\right) \lg \left(y_{i} / u\right), c=1 \\
\sum_{i=1}^{n} p_{i} \lg \left(y_{i} / u\right), c=0
\end{array}\right.
$$

In Equation (1), the parameter $\mathrm{c}$ is used to determine the sensitivity of the exponential change. In general, when $c<2$, the exponential change it determines is sensitive. When $c=0.1$, it is the well-known Theil's index.

Due to its property of dividing overall differences into within-group differences and between-group differences, the Thayer index is widely used in empirical studies of overall spatial heterogeneity, as well as inter-spatial heterogeneity. The calculation formula is

$$
\text { Theil }=\sum_{\mathrm{i}=1}^{\mathrm{n}} \mathrm{T}_{\mathrm{i}} \ln \left(\mathrm{nT}_{\mathrm{i}}\right)=\mathrm{T}_{\mathrm{WR}}+\mathrm{T}_{\mathrm{BR}}
$$


If the area under study is divided into groups according to certain methods, the Theil index can be further decomposed into intra-group differences and inter-group differences.

$$
\begin{gathered}
\mathrm{T}_{\mathrm{WR}}=\sum_{\mathrm{i}=1}^{\mathrm{n}_{\mathrm{db}}} \mathrm{T}_{\mathrm{i}} \ln \left(\mathrm{n}_{\mathrm{db}} \frac{\mathrm{T}_{\mathrm{i}}}{\mathrm{T}_{\mathrm{db}}}\right)+\sum_{\mathrm{i}=1}^{\mathrm{n}_{\mathrm{d}}} \mathrm{T}_{\mathrm{i}} \ln \left(\mathrm{n}_{\mathrm{d}} \frac{\mathrm{T}_{\mathrm{i}}}{\mathrm{T}_{\mathrm{d}}}\right)+\sum_{\mathrm{i}=1}^{\mathrm{n}_{\mathrm{z}}} \mathrm{T}_{\mathrm{i}} \ln \left(\mathrm{n}_{\mathrm{z}} \frac{\mathrm{T}_{\mathrm{i}}}{\mathrm{T}_{\mathrm{z}}}\right)+\sum_{\mathrm{i}=1}^{\mathrm{n}_{\mathrm{x}}} \mathrm{T}_{\mathrm{i}} \ln \left(\mathrm{n}_{\mathrm{x}} \frac{\mathrm{T}_{\mathrm{i}}}{\mathrm{T}_{\mathrm{x}}}\right) \\
\mathrm{T}_{\mathrm{BR}}=\mathrm{T}_{\mathrm{db}} \ln \left(\mathrm{T}_{\mathrm{db}} \frac{\mathrm{n}}{\mathrm{n}_{\mathrm{db}}}\right)+\mathrm{T}_{\mathrm{d}} \ln \left(\mathrm{T}_{\mathrm{d}} \frac{\mathrm{n}}{\mathrm{n}_{\mathrm{d}}}\right)+\mathrm{T}_{\mathrm{z}} \ln \left(\mathrm{T}_{\mathrm{z}} \frac{\mathrm{n}}{\mathrm{n}_{\mathrm{z}}}\right)+\mathrm{T}_{\mathrm{x}} \ln \left(\mathrm{T}_{\mathrm{x}} \frac{\mathrm{n}}{\mathrm{n}_{\mathrm{x}}}\right)
\end{gathered}
$$

In Equations (3)-(5), Theil is Theil index; $n$ is the number of cities in the sample region; $\mathrm{T}_{\mathrm{WR}}$ is the differences within the four regional groups of northeast, east, central, and west regions; $\mathrm{T}_{\mathrm{BR}}$ is the differences between the four regional groups; $\mathrm{n}_{\mathrm{db}}, \mathrm{n}_{\mathrm{d}}, \mathrm{n}_{\mathrm{z}}$, and $\mathrm{n}_{\mathrm{x}}$ are the number of cities within the eastern, eastern, central, and western regions, respectively; $\mathrm{Ti}$ is the carbon emission index of region in and the national average ratio; $T_{d b}, T_{d}, T_{z}$, and $T_{x}$ are the ratios of carbon emission indexes of the northeast, east, central, and west regions to the national average, respectively.

A total of 286 cities at the prefecture level and above are included in our study. The northeast region includes 34 cities in Liaoning, Jilin, and Heilongjiang; the east region includes 87 cities in Beijing, Tianjin, Hebei, Shanghai, Jiangsu, Zhejiang, Shandong, Fujian, Guangdong, and Hainan; the central region includes 80 cities in Shanxi, Henan, Anhui, Hubei, Hunan, and Jiangxi; and the west region includes 85 cities in Inner Mongolia, Chongqing, Sichuan, Guangxi, Guizhou, Yunnan, Shaanxi, Gansu, Ningxia, Tibet, Qinghai, and Xinjiang.

\subsubsection{Correlation Analysis}

The scatter plot is the most visual method used to express correlation analysis. The correlation coefficient is a collective term for a class of indicators that measure the correlation between variables [60-62].

The common correlations are linear correlation, curvilinear correlation, positive correlation, and negative correlation. The Pearson correlation coefficient, also known as the product-difference correlation coefficient, is a common metric for quantitatively describing the degree of linear correlation [63-65]. The formula for measuring the Pearson correlation coefficient is.

$$
r=\frac{\sum\left(x_{i}-\bar{x}\right)\left(y_{i}-\bar{y}\right)}{\sqrt{\left(x_{i}-\bar{x}\right)^{2}} \sqrt{\left(y_{i}-\bar{y}\right)^{2}}}
$$

In Equation (5), $x_{i}$ and $y_{i}$ are the variables, $\bar{x}$ and $\bar{y}$ are the means of variables $x_{i}$ and $y_{i}$, and $r$ is the correlation coefficient. The maximum correlation coefficient is 1 . The closer the absolute value of the correlation coefficient is to 1, the stronger the correlation between the variables. Our study will measure the correlation coefficient between carbon emissions per capita and its influencing variables using correlation coefficients, and visually express the relationship between them by means of scatter plots.

\subsubsection{Principal Component Analysis}

Principal component analysis is a multivariate statistical method for examining correlations among multiple variables, and its application can be reduced to the purposes of data compression and data interpretation [66-70]. Specifically, it examines how the internal structure among multiple variables can be explained by a few principal components. In other words, numerous indicators are substituted for the original indicators by means of dimensionality reduction, but are able to reflect the main content of the source indicators. Usually, $\mathrm{N}$ indicators are linearly combined and downscaled into a new composite indicator.

Often, principal component analysis is more of an intermediate means to an end than an end in itself, and it is often used as an intermediate step in many studies that continue with other multivariate statistical methods, after condensing the data in order to address 
the actual problem [71-74]. In our study, the principal component analysis is followed by a multiple regression analysis to explain the main influencing factors of carbon emissions.

A common method of principal component analysis is to express the variance using $F_{1}$. The larger the variance, the more information is expressed by $F_{1}$, so the maximum value of variance in the linear combination of $F_{1}$ is the first factor. If $F_{1}$ is not sufficient to represent the information of the original $\mathrm{N}$ indicators, then $\mathrm{F}_{2}$ is considered as the second factor, and so on $[75,76]$. The mathematical model of factor analysis is as follows:

$$
\left\{\begin{array}{l}
F_{1}=a_{11} Z X_{1}+a_{21} Z X_{2}+\cdots+a_{p 1} Z X_{p} \\
F_{2}=a_{12} Z X_{1}+a_{22} Z X_{2}+\cdots+a_{p 2} Z X_{p} \\
\cdots \cdots \\
F_{p}=a_{1 m} Z X_{1}+a_{2 m} Z X_{2}+\cdots+a_{p m} Z X_{p}
\end{array}\right.
$$

In Equation (3), $\mathrm{a}_{1 \mathrm{i}}, \mathrm{a}_{2 \mathrm{i}}, \ldots, \mathrm{a}_{\mathrm{pi}}(\mathrm{i}=1,2, \ldots, \mathrm{m})$ are the eigenvectors corresponding to the eigenvalues of the covariance matrix of $X$, and $Z_{1}, Z_{2}, \ldots, Z_{P}$ are the standardized values of the original variables. Factor analysis was performed on the standardized indexes using SPSS statistical analysis software, and the factor principal factors were calculated by KMO and Bartlett's sphericity tests, rotated using the maximum variance method, and finally the factor composite scores were determined.

\subsubsection{Regression Analysis}

Correlation analysis considers only the correlation between variables and does not reveal their causal relationship, while regression analysis is concerned with the causal relationship between variables. Regression analysis is a statistical method that deals with the linear causal relationship between a dependent variable and one or more independent variables. Multiple linear regression models are suitable for analyzing the relationship between a dependent variable and multiple independent variables [60]. Suppose a regression model consists of $\mathrm{p}-1$ independent variables, i.e., $\mathrm{x}_{1}, \mathrm{x}_{2}, \ldots, \mathrm{x}_{\mathrm{p}-1}$, then the regression model can be expressed as:

$$
y_{i}=\beta_{0}+\beta_{1} x_{i 1}+\beta_{2} x_{i 2}+L+\beta_{k} x_{i k}+L+\beta_{(p-1)} x_{i(p-2)}+\varepsilon_{i}
$$

In Equation (7), $y_{i}$ denotes the value of individual $i(i=1,2, \ldots, n)$ in the dependent variable, $\beta_{0}$ is the overall parameter of the intercept $1,2, \ldots, k, \ldots, p-1$ are the overall parameters of the slope. Since this regression model contains multiple independent variables, it is called a multiple regression model. In social science research, we always try to be sure that the model is set up correctly, but sometimes the problem of including irrelevant independent variables in the model may arise. The problem of incorporating irrelevant variables may increase the problem of multi-collinearity and, thus, diminish the validity of the model estimates. Our approach is to use stepwise regression analysis to solve the multi-collinearity problem, making our model estimates more valid and explanatory.

\subsection{Data Sources}

The carbon emission data of 286 cities at prefecture level and above in China were collected from the China City Greenhouse Gases Emission Dataset (2005) and China City Greenhouse Gases Emission Dataset (2015) published by the China Environment Publishing Group and authored by the China Urban Greenhouse Gas Working Group [77]. Data on the influencing factor variables of carbon emissions were collected from China Urban Statistical Yearbook 2016 [78] and China Urban Construction Statistical Yearbook 2015 [79].

Using the quartile method, the per capita carbon emissions (CCE) and total carbon emissions (TCE) of 286 cities at the prefecture level and above in China were divided into four quartiles.

The cities with per capita carbon emissions in the first quartile accounted for 10 cities, those with per capita carbon emissions in the second quartile accounted for 90 cities, those 
with per capita carbon emissions in the third quartile accounted for 93 cities, and those with per capita carbon emissions in the fourth quartile accounted for 93 cities. The highest value of carbon emission per capita is 157.01 tonnes per person (Karamay) and the lowest value is 1.11 tonnes per person (Beijing). There are 54 cities with per capita carbon emissions higher than the average value of 11.59 tonnes per person, accounting for $18.89 \%$. The number of cities with per capita carbon emissions lower than the average value of 11.59 tonnes per person is 232, accounting for $81.11 \%$ (Figure 1 ).

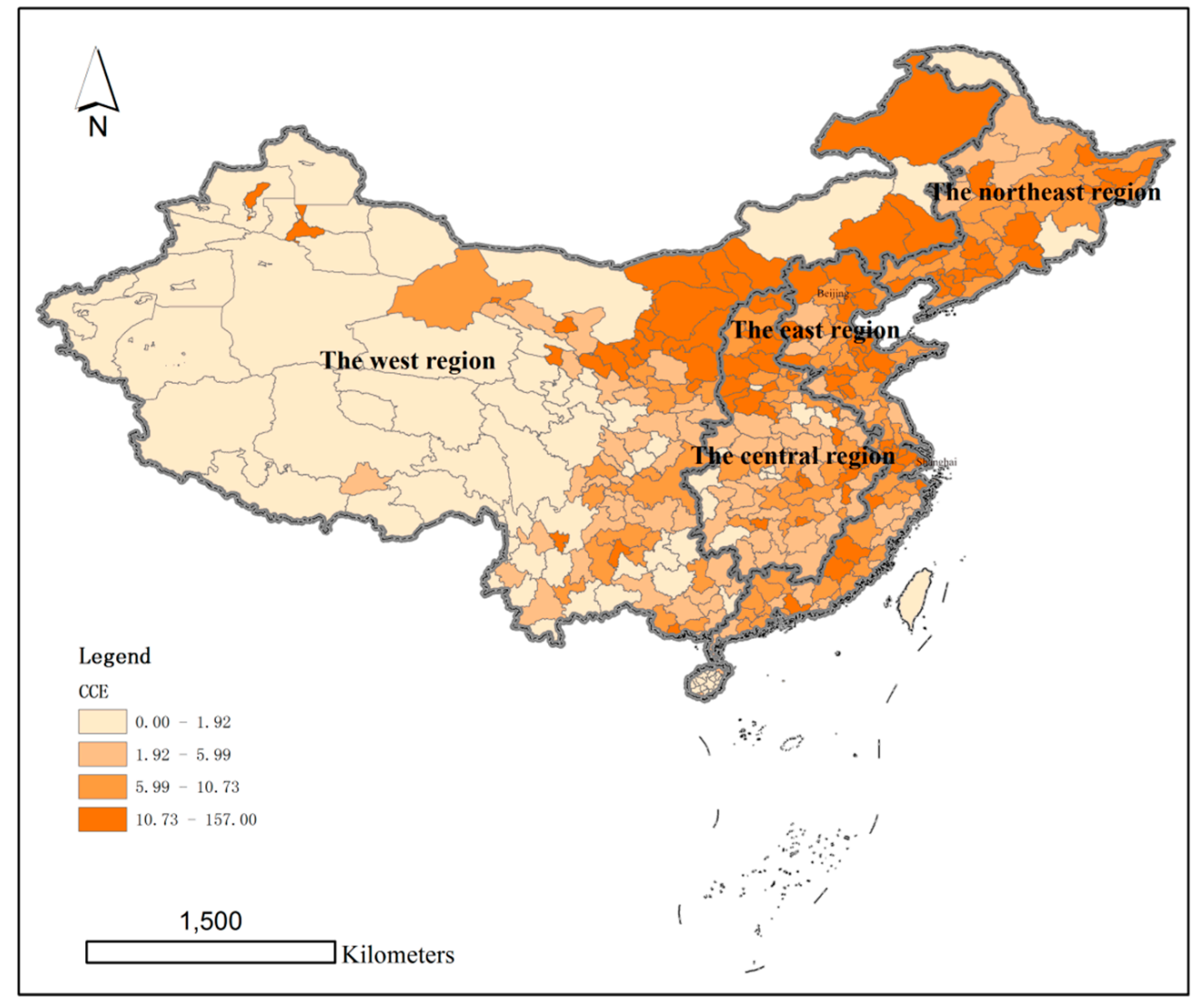

Figure 1. Capita carbon emissions in prefecture-level-and-above cities in China in 2015 (t/person).

The cities with total carbon emissions in the first quartile numbered 10, the cities with total carbon emissions in the second quartile numbered 91, the cities with total carbon emissions in the third quartile numbered 93, and the cities with total carbon emissions in the fourth quartile numbered 92. The highest value of total carbon emission is 276,773,200 tonnes (Shanghai) and the lowest value is 2,422,300 tonnes (Lhasa). There are 97 cities with total carbon emissions above the average value of 39.5042 million tonnes, accounting for $33.92 \%$. There are 189 cities with total carbon emissions lower than the average value of 39.5042 million tonnes, accounting for $66.08 \%$ (Figure 2). 


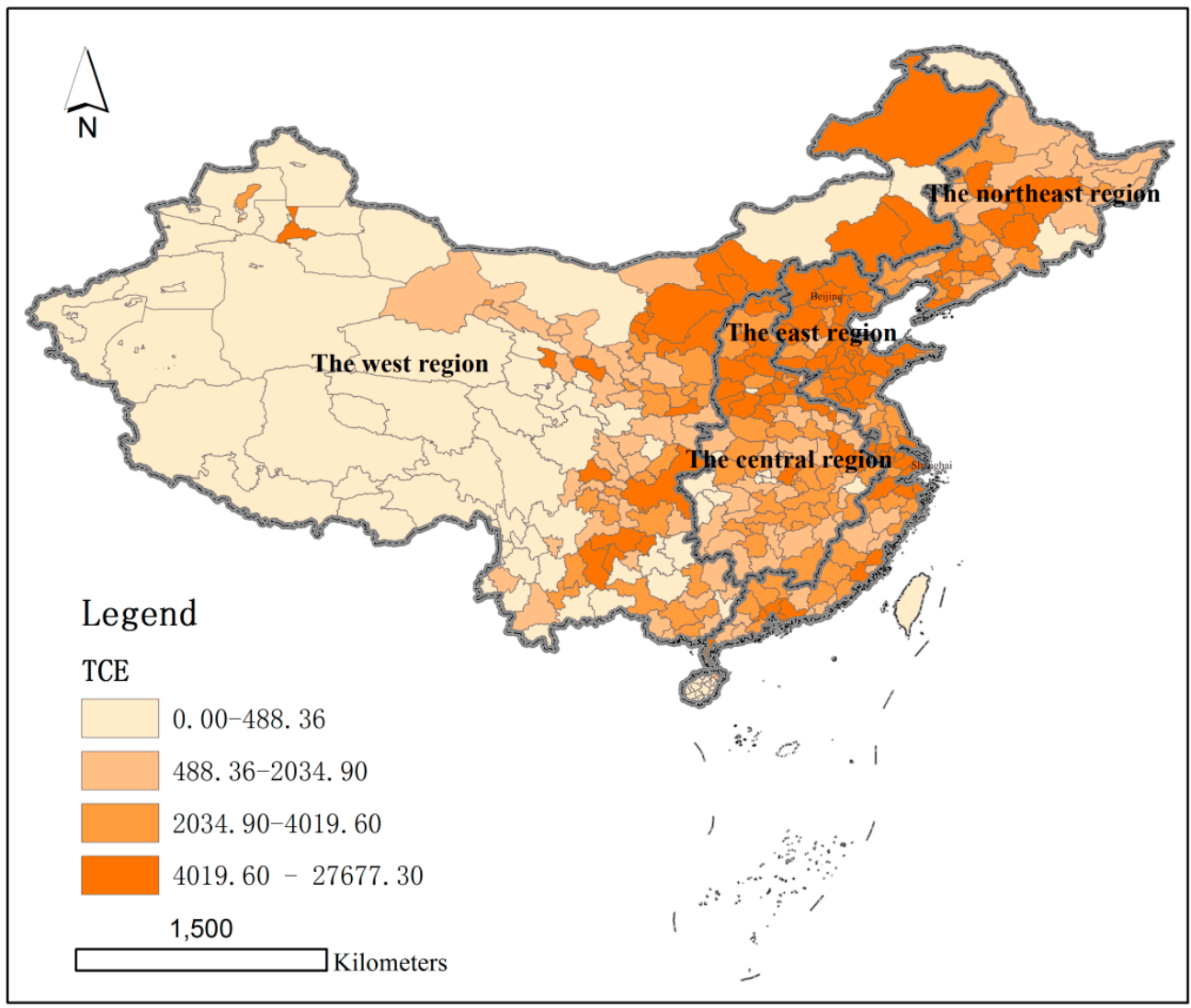

Figure 2. Total carbon emissions in prefecture-level-and-above cities in China in 2015(10 4 tonnes).

\section{Analysis of Regional Differences in Carbon Emissions}

3.1. Decomposition of Regional Differences in Carbon Emissions

\subsubsection{Within-Group Differences, between Group Differences, and Total Differences}

From the measurement of spatial heterogeneity of carbon emissions in 20 sectors in China, the following information was derived (Table 1).

First, regional differences widened for six sectors: urban household carbon emissions, railway carbon emissions, aviation carbon emissions, carbon emissions per unit of GDP, carbon emissions per unit of GDP in the primary industry, and carbon emissions per unit of GDP in the secondary industry, while for rural household carbon emissions, agricultural carbon emissions, industrial carbon emissions, service carbon emissions, road carbon emissions, water navigation carbon emissions, transportation carbon emissions, direct carbon emissions, indirect carbon emissions, total carbon emissions, per capita carbon emissions, carbon emissions per unit of land area, carbon emissions per unit of GDP in the tertiary sector, and carbon productivity they narrowed; the regional differences in 14 sectors narrowed.

Second, the main reason for the widening of regional differences in six sectors is that the intra-group differences in carbon emissions have increased more than the inter-group differences. For example, the intra-group variance coefficient for urban household carbon emissions expanded from 0.485 in 2005, to 0.685 in 2015, an increase of $20.00 \%$ in the intragroup variance and $-3.50 \%$ in the inter-group variance. In other words, the within-group variation in urban household carbon emissions is higher than the between-group variation, leading to a widening of the total variation in urban household carbon emissions. 
Table 1. Within-group differences, between group differences, and total differences.

\begin{tabular}{ccccccc}
\hline \multirow{2}{*}{ Theil Index } & \multicolumn{2}{c}{ Within-Group Differences } & Between Group Differences & \multicolumn{2}{c}{ Total Differences } \\
\cline { 2 - 6 } Indicators & $\mathbf{2 0 0 5 a}$ & $\mathbf{2 0 1 5 b}$ & $\mathbf{2 0 0 5 a}$ & $\mathbf{2 0 1 5 b}$ & $\mathbf{2 0 0 5 a}$ & $\mathbf{2 0 1 5 b}$ \\
\hline Urban Household & 0.485 & 0.685 & 0.045 & 0.010 & 0.529 & 0.695 \\
Rural Household & 0.810 & 0.772 & 0.087 & 0.012 & 0.897 & 0.784 \\
Agriculture & 0.374 & 0.347 & 0.034 & 0.012 & 0.408 & 0.359 \\
Industry & 0.415 & 0.363 & 0.045 & 0.025 & 0.460 & 0.387 \\
Service & 0.801 & 0.703 & 0.005 & 0.028 & 0.806 & 0.731 \\
Road & 0.267 & 0.254 & 0.124 & 0.050 & 0.392 & 0.304 \\
Railway & 0.372 & 0.381 & 0.014 & 0.011 & 0.387 & 0.392 \\
Waterborne Navigation & 1.173 & 1.177 & 0.632 & 0.333 & 1.805 & 1.510 \\
Aviation & 1.778 & 2.161 & 0.415 & 0.365 & 2.193 & 2.526 \\
Transportation & 0.305 & 0.307 & 0.144 & 0.070 & 0.449 & 0.377 \\
Direct Emission & 0.366 & 0.316 & 0.047 & 0.025 & 0.412 & 0.340 \\
Indirect Emission & 1.495 & 0.951 & 0.251 & 0.218 & 1.746 & 1.169 \\
Total Emission & 0.369 & 0.307 & 0.052 & 0.035 & 0.421 & 0.341 \\
Capita Carbon Emission & 0.455 & 0.435 & 0.016 & 0.027 & 0.471 & 0.463 \\
Per Land Area Emission & 0.524 & 0.470 & 0.107 & 0.095 & 0.631 & 0.565 \\
Carbon Emissions per GDP & 0.261 & 0.304 & 0.028 & 0.027 & 0.289 & 0.331 \\
Primary Industry & 0.250 & 0.258 & 0.008 & 0.006 & 0.257 & 0.263 \\
Secondary Industry & 0.286 & 0.387 & 0.046 & 0.045 & 0.332 & 0.431 \\
Tertiary Industry & 0.474 & 0.152 & 0.122 & 0.047 & 0.595 & 0.200 \\
Carbon Productivity & 0.216 & 0.198 & 0.024 & 0.012 & 0.240 & 0.211 \\
\hline
\end{tabular}

Third, there are two main reasons for the narrowing of regional differences across the 14 sectors: one reason is that both intra-group and inter-group differences in carbon emissions across the 14 sectors appear to have narrowed, leading to a narrowing of the total difference. For example, the increase in intra-group and inter-group differences in carbon emissions for rural households was $-3.80 \%$ and $-7.50 \%$, respectively, while the increase in the total difference was $-11.30 \%$. Second, the sum of the increase in intra-group and inter-group differences in carbon emissions for 14 sectors was negative. For example, the increase in the intra-group variance of carbon emissions in the service sector was -9.805 , while the increase in the inter-group variance was $2.30 \%$, resulting in the total variance of carbon emissions in the service sector remaining negative and the total variance showing a narrowing trend.

A preliminary analysis of the main reasons for the changes in spatial heterogeneity of carbon emissions in 20 sectors: (1) Regional differences in China's carbon emissions are the result of the interaction of various forces, including the forces of urbanization, industrialization, policy reform, and economic development, etc. The way towards modernization of China's low-carbon emission reduction involves from the intertwining and interaction of these forces. (2) The coefficients of variation in carbon emissions from urban households, railway carbon emissions, aviation carbon emissions, and carbon emissions per unit of GDP from secondary industries have become larger, precisely reflecting the process of industrialization and the rapid development of modern China. The years 2005-2015 saw a period of rapid urbanization in China, with China's urbanization rate rising sharply from $42.99 \%$ in 2005 , to $56.10 \%$ in 2015 . During this period, China's urban population increased sharply, from 562.12 million in 2005 , to 771.16 million, a cumulative increase of 209.04 million in the urban population, which means a large influx of rural population into the cities. As such, they need a large amount of consumption and generate a large amount of carbon emissions, which invariably brings about changes in regional differences in carbon emissions of urban households. Similarly, in the process of rapid modernization, China has invested tremendously in infrastructure, with social fixed asset investment amounting to RMB 8877.36 billion in 2005 and increasing to RMB 5619.98 billion in 2015, an expansion 
of 6.33 times in the last 11 years. Obviously, the infrastructure construction invested in with a huge amount of capital has brought about an increase in energy consumption, and to some extent, a change in the spatial heterogeneity of carbon emissions in railways, aviation, and other sectors.

\subsubsection{Decomposition of within Group Differences in Four Regions of China}

A further analysis of the spatial heterogeneity of carbon emissions in 20 sectors in China revealed the following intra-group differences among the northeastern, eastern, central, and western regions of China (Table 2):

Table 2. Within group differences in four regions of China.

\begin{tabular}{|c|c|c|c|c|c|c|c|c|}
\hline \multirow[b]{2}{*}{ Indicators } & \multicolumn{2}{|c|}{ Northeast Region } & \multicolumn{2}{|c|}{ Eastern Region } & \multicolumn{2}{|c|}{ Central Region } & \multicolumn{2}{|c|}{ Western Region } \\
\hline & $2005 a$ & $2015 b$ & $2005 a$ & $2015 b$ & 2005a & $2015 b$ & $2005 a$ & $2015 b$ \\
\hline Urban Household & 0.040 & 0.035 & 0.207 & 0.229 & 0.053 & 0.057 & 0.185 & 0.363 \\
\hline Rural Household & 0.013 & 0.017 & 0.157 & 0.413 & 0.079 & 0.113 & 0.561 & 0.229 \\
\hline Agriculture & 0.026 & 0.044 & 0.104 & 0.090 & 0.062 & 0.080 & 0.183 & 0.133 \\
\hline Industry & 0.025 & 0.020 & 0.210 & 0.127 & 0.071 & 0.082 & 0.109 & 0.133 \\
\hline Service & 0.085 & 0.083 & 0.193 & 0.275 & 0.169 & 0.073 & 0.353 & 0.273 \\
\hline Road & 0.035 & 0.022 & 0.139 & 0.132 & 0.035 & 0.032 & 0.058 & 0.069 \\
\hline Railway & 0.021 & 0.012 & 0.198 & 0.198 & 0.049 & 0.057 & 0.104 & 0.113 \\
\hline Waterborne Navigation & 0.019 & 0.116 & 0.950 & 0.702 & 0.050 & 0.163 & 0.154 & 0.197 \\
\hline Aviation & 0.051 & 0.077 & 1.462 & 1.511 & 0.075 & 0.168 & 0.189 & 0.406 \\
\hline Transportation & 0.031 & 0.023 & 0.189 & 0.174 & 0.031 & 0.032 & 0.055 & 0.078 \\
\hline Direct Emission & 0.023 & 0.017 & 0.186 & 0.119 & 0.059 & 0.063 & 0.098 & 0.116 \\
\hline Indirect Emission & 0.220 & 0.071 & 0.922 & 0.543 & 0.142 & 0.121 & 0.211 & 0.217 \\
\hline Total Emission & 0.027 & 0.017 & 0.194 & 0.125 & 0.055 & 0.056 & 0.093 & 0.108 \\
\hline Capita Carbon Emission & 0.016 & 0.028 & 0.060 & 0.040 & 0.073 & 0.064 & 0.306 & 0.303 \\
\hline Per Land Area Emission & 0.025 & 0.032 & 0.229 & 0.177 & 0.152 & 0.152 & 0.118 & 0.110 \\
\hline Carbon emissions per GDP & 0.013 & 0.041 & 0.046 & 0.038 & 0.059 & 0.088 & 0.142 & 0.137 \\
\hline Primary Industry & 0.013 & 0.023 & 0.052 & 0.067 & 0.096 & 0.079 & 0.089 & 0.088 \\
\hline Secondary Industry & 0.029 & 0.083 & 0.063 & 0.054 & 0.060 & 0.115 & 0.135 & 0.136 \\
\hline Tertiary Industry & 0.063 & 0.054 & 0.016 & 0.032 & 0.122 & 0.025 & 0.273 & 0.042 \\
\hline Carbon Productivity & 0.008 & 0.013 & 0.076 & 0.057 & 0.050 & 0.055 & 0.082 & 0.072 \\
\hline
\end{tabular}

First, the within-group differences in six sectors, namely urban household carbon emissions, railway carbon emissions, aviation carbon emissions, carbon emissions per unit of GDP, carbon emissions per unit of GDP in the primary industry, and carbon emissions per unit of GDP in the secondary industry, are significant, as shown by the different contributions of the within-group differences in carbon emissions in the six sectors in the northeast, eastern, central, and western regions. In terms of urban household carbon emissions, the increase in intra-group variation in the western region was significantly higher than that in the other three regions. In the railway sector, the within-group differences in the central and western regions widened slightly, while the within-group differences in the northeastern region showed a narrowing trend. In the aviation sector, the highest contribution to intra-group variation in carbon emissions was made by the western region, where the intra-group variation increased by $21.70 \%$, while the increase in the eastern region and the eastern region was $4.90 \%$ and $2.60 \%$, respectively; significantly lower than that of the western region. In terms of carbon emissions per unit of GDP in the secondary sector, the within-group difference in carbon emissions widened by more than $5.00 \%$ in both the eastern and central regions, while the within-group difference increased or decreased by less than $1.00 \%$ in both the eastern and western regions.

Second, within-group differences in carbon emissions from rural households, carbon emissions from water navigation, indirect carbon emissions, and carbon emissions per unit 
of GDP from the tertiary sector were significant across the 14 sectors. For rural household carbon emissions, the intra-group variation in the eastern region showed a widening trend, with the intra-group variation coefficient increasing by $25.60 \%$ from 2005 to 2015 , while the intra-group variation in the western region showed a narrowing trend, with the intra-group variation increasing by $-33.20 \%$. In terms of carbon emissions from water navigation, the intra-group variation coefficients of the northeast, east, central and west regions increased by $9.70 \%,-24.80 \%, 11.30 \%$, and $4.30 \%$, respectively. In terms of indirect carbon emissions, the intra-group differences in the northeastern and eastern regions showed a significant reduction, while the intra-group differences in the central and western regions fluctuated by $-2.10 \%$ and $0.60 \%$, respectively. In terms of carbon emissions per unit of GDP in the tertiary sector, the within-group variation in the western region showed the largest change, with an increase of $-23.10 \%$, while the changes in the northeastern and eastern regions were smaller, at $-0.90 \%$ and $1.60 \%$, respectively.

To a large extent, the spatial heterogeneity of carbon emissions across the 20 sectors in China's four regions was brought about by the varying magnitude of intra-group differences. The direct cause of the spatial heterogeneity of carbon emissions across the 20 sectors in China and its explanation requires a visual analysis of the carbon emissions data for each sector. Next, we will compare carbon emissions across the 20 sectors in the four regions. Prior to the comparative analysis, we group the 20 sectors into seven categories: carbon emissions from urban and rural households, carbon emissions from agriculture, industry and services, carbon emissions from roads, railways, water transport and aviation, carbon emissions per capita and carbon emissions per land area, direct and indirect carbon emissions, carbon emissions per unit of GDP, and carbon productivity.

\subsection{Decomposition of Carbon Emissions}

\subsubsection{Carbon Emissions from Urban and Rural Households}

Looking at the total carbon emissions of urban and rural households, it is very surprising to find that the carbon emissions of rural households in China are higher than those of urban households. The carbon emissions ratio of urban households to rural household was 0.68 in 2005, rising to 0.71 in 2015, i.e., the carbon emissions of rural households are higher than those of urban households. The total carbon emissions of both urban and rural households showed a declining trend, with urban household carbon emissions in China's 286 prefecture-level-and-above cities amounting to 126,499,400 tonnes in 2005, falling to $98,665,600$ tonnes in 2015 , a decline of $22 \%$. The carbon emissions of rural households in China's 286 prefecture-level-and-above cities were 187,145,400 tonnes in 2005, declining to $139,537,200$ tonnes in 2015 , a decline of $25.44 \%$. In terms of the average amount of carbon emissions of urban and rural households, it is still the case that the per capita carbon emissions of rural households in China are higher than those of urban households. The average carbon emissions of households in China's 286 prefecture-level- and-above cities was 654,400 tonnes in 2005, and the average dropped to 487,900 tonnes in 2015, a decrease of $25.44 \%$ (Table 3 ).

Table 3. Carbon emissions from urban and rural households.

\begin{tabular}{|c|c|c|c|c|c|}
\hline \multirow{2}{*}{ Region } & \multirow[t]{2}{*}{ Carbon Emission } & \multicolumn{2}{|c|}{ Urban Households ( $10^{4}$ tonnes) } & \multicolumn{2}{|c|}{ Rural Households ( $10^{4}$ tonnes) } \\
\hline & & $2005 a$ & $2015 a$ & $2005 a$ & $2015 a$ \\
\hline & Northeast Region & 45.70 & 29.86 & 20.21 & 33.61 \\
\hline & Eastern Region & 63.82 & 40.73 & 57.66 & 51.49 \\
\hline & Central Region & 32.38 & 29.05 & 53.65 & 56.75 \\
\hline & Western Region & 34.75 & 35.10 & 102.57 & 44.59 \\
\hline
\end{tabular}

In terms of the average carbon emissions of urban and rural households in the four regions, although urban households in eastern China had the largest average carbon emissions, they have also seen the largest reduction in carbon emissions, from 638,200 tonnes to 
407,300 tonnes, between 2005 and 2015, a reduction of 36.17\%. Although rural households in northeast China had the smallest average carbon emissions, they also had the largest increase in carbon emissions. The average carbon emissions of rural households in Northeast China rose from 202,100 tonnes in 2005, to 336,100 tonnes in 2015, an increase of $66.31 \%$. In addition, urban households in western China and rural households in central China also saw a small increase in carbon emissions.

\subsubsection{Carbon Emissions from Agriculture, Industry, and Services}

From 2005 to 2015, China's carbon emissions from the three major sectors of agriculture, industry, and services all increased significantly. In terms of the total carbon emissions from the three major sectors, in 2005, the total carbon emissions from the agricultural sector, industrial sector, and service sector in 286 prefecture-level-and-above cities in China were 73,116,900 tonnes, 54,914,300 tonnes, and 63,236,400 tonnes, respectively, while in 2015, the total carbon emissions of the agricultural sector, industrial sector, and service sector were 95,211,900 tonnes, 88,753,800 tonnes, and 284,754,600 tonnes, respectively; with the total carbon emissions of the three major sectors increasing by 1.30 times, 1.62 times, and 4.50 times, respectively. In terms of the average amount of carbon emissions from the three major sectors, in 2005, the average carbon emissions from the agricultural sector, industrial sector, and service sector in 286 prefecture-level-and-above cities in China were 255,700 tonnes, 19,199,400 tonnes and 221,100 tonnes respectively; in 2015, the average carbon emissions from the agricultural sector, industrial sector and service sector were 332,900 tonnes, 31,033,700 tonnes, and 995,600 tonnes, respectively.

In terms of the average carbon emissions of the four major regions in China, the average carbon emissions of the agricultural sector in the northeastern, eastern, central, and western regions of China were 289,800 tonnes, 338,000 tonnes, 240,800 tonnes, and 171,700 tonnes in 2005, respectively. The average carbon emissions of the agricultural sector in the northeastern, eastern, central, and western regions were 429,900 tonnes, 348,400 tonnes, 346,500 tonnes, and 265,400 tonnes in 2015, respectively. In addition, from 2005 to 2015, the average carbon emissions of both industry and services in the four major regions of China increased significantly, with the fastest growth being in the services sector in the northeast, where the average carbon emissions expanded by 7.65 times, and with the slowest growth being in the agriculture sector in the east, where the average carbon emissions expanded by 1.03 times (Table 4).

Table 4. Comparison of the average value of carbon emissions from the agricultural, industrial, and service sectors in the four major regions of China (unit: $10^{4}$ tonnes).

\begin{tabular}{|c|c|c|c|c|c|c|c|}
\hline \multirow{2}{*}{ Region } & \multirow{2}{*}{ Carbon Emission } & \multicolumn{2}{|c|}{ Agricultural Sector } & \multicolumn{2}{|c|}{ Industrial Sector } & \multicolumn{2}{|c|}{ Service Industry Sector } \\
\hline & & $2005 a$ & $2015 a$ & $2005 a$ & 2015a & 2005a & $2015 a$ \\
\hline & Northeast Region & 28.98 & 42.99 & 1775.30 & 2536.60 & 21.11 & 161.60 \\
\hline & Eastern Region & 33.80 & 34.84 & 2804.79 & 4172.50 & 20.88 & 98.72 \\
\hline & Central Region & 24.08 & 34.65 & 1559.78 & 2718.36 & 20.35 & 75.56 \\
\hline & Western Region & 17.17 & 26.54 & 1411.08 & 2598.15 & 25.42 & 98.21 \\
\hline
\end{tabular}

\subsubsection{Carbon Emissions from Road, Railway, Waterborne Navigation, and Aviation}

The period 2005-2015 was one of the most intensive periods in China for the construction of 'iron and public infrastructure', i.e., railway, highway, airport, water conservancy, and other major infrastructure. In terms of total carbon emissions from the road, railway, water transport, and aviation sectors, the total carbon emissions from 286 cities at prefecture level and above in China were 298,542,000 tonnes, 13,446,700 tonnes, 23,083,800 tonnes, and $19,733,400$ tonnes in 2005, respectively, while the total carbon emissions from road, railway, water transport, and aviation were 63,964,300 tonnes, 7,637,400 tonnes 40,980,000 tonnes, and 55,426,200 tonnes in 2015, respectively, with the total carbon emissions of the four major industries increasing by 2.14 times, 0.57 times, 1.78 times, and 2.81 times, respectively. 
In terms of the average amount of carbon emissions from the road, railway, water transport, and aviation sectors, the average carbon emissions from 286 prefecture-level-and-above cities in China were 1,043,900 tonnes, 47,000 tonnes, 80,700 tonnes, and 69,000 tonnes for road, railway, water transport, and aviation in 2005, respectively; the average carbon emissions from road, railway, water transport, and aviation were 2,363,500 tonnes, 267,700 tonnes million tonnes, 143,300 tonnes, and 193,800 tonnes in 2015, respectively. The average carbon emissions of these four sectors increased by 1,192,700 tonnes, $-20,300$ tonnes, 62,600 tonnes, and 124,800 tonnes, respectively.

Looking at the total carbon emissions of China's four major regions, the total carbon emissions of urban roads, railways, water transport, and aviation in the northeast expanded by $1.71,0.40,3.34$, and 2.48 times, respectively. The total carbon emissions of urban roads, railways, water transport, and aviation in the eastern region expanded by 1.84 times, 0.61 times, 1.43 times, and 2.68 times, respectively. The total carbon emissions of urban roads, railways, water transport, and aviation in the central region increased by 2.80 times, 0.53 times, 4.65 times, and 3.20 times, respectively. The total carbon emissions of urban roads, railways, water transport, and aviation in the western region expanded by 2.76 times, 0.65 times, 2.41 times, and 3.31 times, respectively.

In terms of the average amount of carbon emissions in China's four major regions, the average carbon emissions from roads in northeast, east, central and west China were 1.138 million tonnes, 48.1 million tonnes, 16.3 million tonnes, and 22.7 million tonnes in 2005, respectively, and the average carbon emissions of the agricultural sector in northeast, east, central and west China were 1.9442 million tonnes, 19.3 million tonnes, 54.4 million tonnes, and 56.2 million tonnes in 2015. From 2005 to 2015, the average values of carbon emissions of road, water transport, and aviation in the four major regions of China all increased significantly, and only the average value of carbon emissions from railways decreased significantly (Table 5).

Table 5. Comparison of the average value of carbon emissions from road, railway, waterborne navigation, and aviation in the four major regions of China (Unit: $10^{4}$ tonnes).

\begin{tabular}{ccccccccc}
\hline \multirow{2}{*}{ Carbon Emission } & \multicolumn{2}{c}{ Road } & \multicolumn{2}{c}{ Railway } & \multicolumn{2}{c}{ Waterborne Navigation } & Aviation \\
\cline { 2 - 9 } Region & 2005a & 2015a & 2005a & 2015a & 2005a & 2015a & 2005a & 2015a \\
\hline Northeast Region & 113.80 & 194.42 & 4.81 & 1.93 & 1.63 & 5.44 & 2.27 & 5.62 \\
Eastern Region & 181.15 & 332.58 & 4.89 & 2.98 & 22.41 & 31.96 & 16.67 & 44.67 \\
Central Region & 65.91 & 184.51 & 5.62 & 2.99 & 2.24 & 10.42 & 1.47 & 4.72 \\
Western Region & 58.26 & 160.69 & 3.60 & 2.35 & 1.46 & 3.52 & 3.86 & 12.79 \\
\hline
\end{tabular}

\subsubsection{Capita Carbon Emission and Per Land Area Emissions}

Both, in terms of carbon emissions per capita and carbon emissions per land area, China's carbon emissions have shown a rapid increase from 2005 to 2015. The carbon emissions per capita in China's 286 prefecture-level-and-above cities were 6.82 tonnes per person in 2005, increasing to 11.59 tonnes per person in 2015, an expansion of 1.79 times, compared to the carbon emissions per capita in China's 286 prefecture-level-and-above cities in 2005. The carbon emissions per capita in China's 286 prefecture-level-and-above cities were 2737.03 tonnes $/ \mathrm{km}^{2}$ in 2005 , increasing to 4613.11 tonnes $/ \mathrm{km}^{2}$, an expansion of 1.69 times.

Looking at the average carbon emissions of China's four major regions, from 2005 to 2015 , carbon emissions per capita increased the most in the western region (expanding by 1.83 times), while carbon emissions per capita increased the least in the eastern region (expanding by 1.56 times). The eastern region had the largest ground average carbon emission intensity, with its average value increasing from 4523.48 tonnes $/ \mathrm{km}^{2}$ in 2005 to 7407.01 tonnes $/ \mathrm{km}^{2}$ in 2015 . The western region had the smallest ground average carbon emission intensity (2521.93 tonnes $/ \mathrm{km}^{2}$ in 2015 ); in terms of carbon emission increase, 
from 2005 to 2015, the northeast, eastern, central eastern, and western regions expanded by 1.68 times, 1.64 times, 1.72 times, and 1.78 times, respectively (Table 6).

Table 6. Comparison of the average value of capita carbon emission and per land area emissions in four major regions of China (Unit: $\mathrm{t} /$ person; $\mathrm{t} / \mathrm{km}^{2}$ ).

\begin{tabular}{cccccc}
\hline \multirow{2}{*}{ Region } & Carbon Emission & \multicolumn{2}{c}{ Capita Carbon Emission } & \multicolumn{2}{c}{ Per Land Area Emissions } \\
\cline { 3 - 6 } & & $\mathbf{2 0 0 5 a}$ & $\mathbf{2 0 1 5 a}$ & 2005a & 2015a \\
\hline \multirow{2}{*}{ Northeast Region } & 7.65 & 12.84 & 1655.73 & 2774.71 \\
& Eastern Region & 6.17 & 9.65 & 4523.48 & 7407.01 \\
& Central Region & 5.45 & 9.05 & 2660.63 & 4577.92 \\
& Western Region & 8.44 & 15.46 & 1412.97 & 2521.93 \\
\hline
\end{tabular}

\subsubsection{Direct and Indirect Carbon Emission}

From 2005 to 2015, both direct and indirect carbon emissions in China showed a significant increase, with indirect carbon emissions growing significantly faster than direct carbon emissions. In terms of total emissions volume, from 2005 to 2015, the total direct carbon emissions of 286 prefecture-level-and-above cities in China increased 1.64 times, from $624,769.85$ million tonnes to $1,027,499.3$ million tonnes. Total indirect carbon emissions increased 2.74 times, from 386,745,800 tonnes to 106,069,600 tonnes. In terms of average volume, from 2005 to 2015, the average direct carbon emissions of 286 prefecture-level-andabove cities in China increased from 21,845,100 tonnes to 35,795,500 tonnes, an increase of $13,950,400$ tonnes. The average indirect carbon emissions increased from $1,352,300$ tonnes to $3,708,700$ tonnes, an increase of 2,356,500 tonnes.

In terms of direct carbon emissions in the four regions, from 2005 to 2015, direct carbon emissions in cities in the northeast, east, central, and west regions increased by 1.50 times, 1.50 times, 1.77 times and 1.86 times, respectively. In terms of indirect carbon emissions from the four regions, from 2005 to 2015, indirect carbon emissions from cities in the northeast, east, central, and west regions increased by 1.3558 million tonnes, 43.6385 million tonnes, 11.243 million tonnes, and 123.252 million tonnes, respectively. Looking at the average carbon emissions of the four major regions in China, the eastern region had the highest average direct carbon emissions, while the western region had the lowest average direct carbon emissions. The central region had the lowest average indirect carbon emissions, while the eastern region still had the highest average indirect carbon emissions (Table 7).

Table 7. Comparison of the average value of direct and indirect carbon emissions in four major regions of China (Unit: $10^{4}$ tonnes).

\begin{tabular}{cccccc}
\hline \multirow{2}{*}{ Region } & Carbon Emission & \multicolumn{2}{c}{ Direct Emission } & \multicolumn{2}{c}{ Indirect Emission } \\
\cline { 4 - 6 } & & 2005a & 2015a & 2005a & 2015a \\
\cline { 4 - 6 } & & 2013.81 & 3012.06 & 205.78 & 209.77 \\
& Northeast Region & 3206.04 & 4810.49 & 258.26 & 760.15 \\
& Eastern Region & 1765.50 & 3117.02 & 39.83 & 180.37 \\
& Central Region & 1601.58 & 2981.94 & 70.85 & 216.18 \\
\hline
\end{tabular}

\subsubsection{Carbon Emissions per GDP and Carbon Productivity}

Carbon emission per unit GDP reflects carbon emission intensity, and carbon productivity reflects the opposite indicator, i.e., the larger the carbon emission per unit GDP, the higher the carbon emission intensity and the lower the carbon productivity. The smaller the carbon emission per unit GDP, and the higher the carbon productivity.

In 2005, the average carbon emission per unit GDP in 286 prefecture-level-and-above cities in China was 4.68 tonnes/yuan, which dropped to 2.37 tonnes/yuan in 2015, a 
decrease of $49.32 \%$. In 2005, the average carbon emission per unit GDP in the primary, secondary and tertiary industries in Chinese cities was 0.38 tonnes/yuan, 8.62 tonnes/yuan, and 0.12 tonnes/yuan. In 2015, the average carbon emission per unit GDP in the primary, secondary, and tertiary industries was 0.38 tonnes/yuan, 8.62 tonnes/yuan, and 0.12 tonnes/yuan, respectively (Table 8).

Table 8. Comparison of the carbon emissions per primary industry, secondary industry, and tertiary industry in four major regions of China (Unit: tonnes $¥ ¥ 10,000$ ).

\begin{tabular}{|c|c|c|c|c|c|c|c|}
\hline \multirow{2}{*}{ Region } & \multirow[t]{2}{*}{ Carbon Emission } & \multicolumn{2}{|c|}{ Primary Industry } & \multicolumn{2}{|c|}{ Secondary Industry } & \multicolumn{2}{|c|}{ Tertiary Industry } \\
\hline & & 2005a & 2015a & 2005a & 2015a & 2005a & 2015a \\
\hline & Northeast Region & 0.45 & 0.23 & 12.18 & 7.01 & 0.14 & 0.85 \\
\hline & Eastern Region & 0.37 & 0.17 & 5.36 & 2.79 & 0.05 & 0.33 \\
\hline & Central Region & 0.42 & 0.21 & 8.05 & 4.01 & 0.12 & 0.46 \\
\hline & Western Region & 0.32 & 0.18 & 11.09 & 4.82 & 0.20 & 0.58 \\
\hline
\end{tabular}

Looking at the four major regions, from 2005 to 2015, the average carbon emissions of the primary and secondary industries in the northeastern, eastern, central, and western regions of China all declined significantly, while the average carbon emissions of the tertiary industry increased (Figure 3).

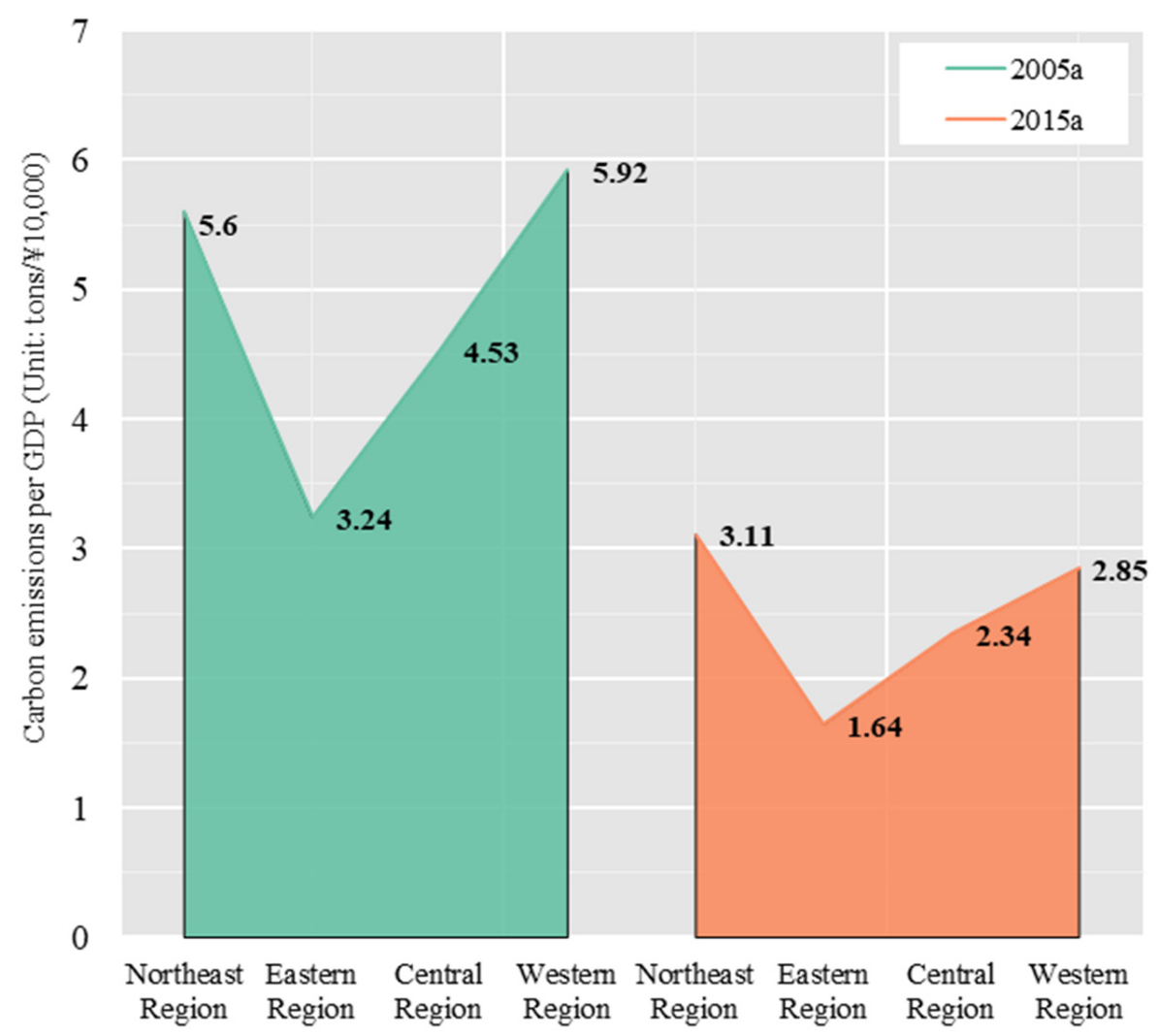

Figure 3. Carbon emissions per GDP in four major regions of China.

In terms of the total and average carbon emissions by sector from 2005-2015, in China's 286 cities they are expanding, but surprisingly, in terms of carbon emissions per unit GDP and average carbon emissions per unit GDP from primary, secondary, and tertiary industries, the overall carbon emission intensity of China's 286 cities decreased, implying that China has taken steps towards low carbon emission reduction and put measures into practice. 
Carbon productivity is the opposite indicator of carbon emissions per unit GDP. The higher the carbon productivity, the better the effect of low-carbon emission reduction. Whether looking at the 286 cities in general or the four major regions of China, China's carbon productivity generally showed an increasing trend from 2005 to 2015, indicating that China's carbon emission reduction efforts achieved some success, and the change in this indicator is verified with the change in carbon emissions per unit of GDP and the change in average carbon emissions per unit GDP in the primary, secondary, and tertiary industries. Specifically, carbon productivity in China's 286 prefecture-level and above cities increased 1.95 times, from 0.37 million yuan/tonnes in 2005 to 0.72 million yuan/tonnes in 2015. From 2005 to 2015, carbon productivity increased faster in four major regions in China, from 0.22 to 0.49 million yuan/tonnes in the northeast, from 0.47 to 0.85 million yuan/tonnes in the east, from 0.34 to 0.72 million yuan/tonnes in the central region, and from 0.34 to 0.67 million yuan/tonnes in the west (Figure 4 ).

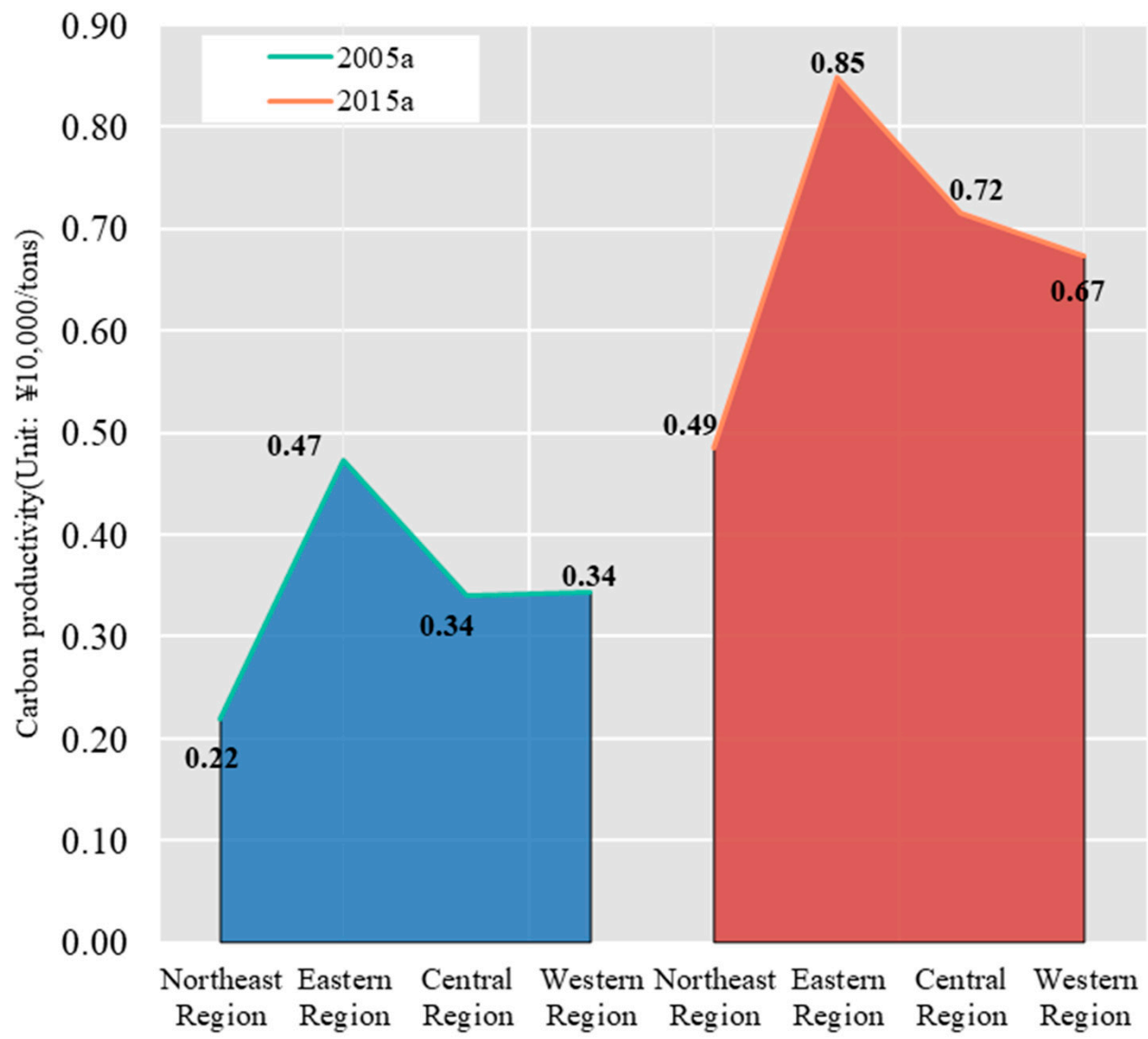

Figure 4. Carbon productivity in four major regions of China.

\section{Analysis of the Influencing Factors of Carbon Emissions}

\subsection{Correlation Analysis}

To explore the relationship between the carbon emissions per capita and the economic, social, and ecological variables, we selected eight variables for analysis, which are GRP per capita (GRP), industrial sulfur dioxide emission per capita $\left(\mathrm{SO}_{2}\right)$, greening coverage of built-up areas (GCA), population density (PD), proportion of urban construction land to urban area (UCL), proportion of employees in secondary sector (ESS), proportion of employees in tertiary sector (ETS), and retail sales of social consumer goods per capita (RSS) (Figure 5). 

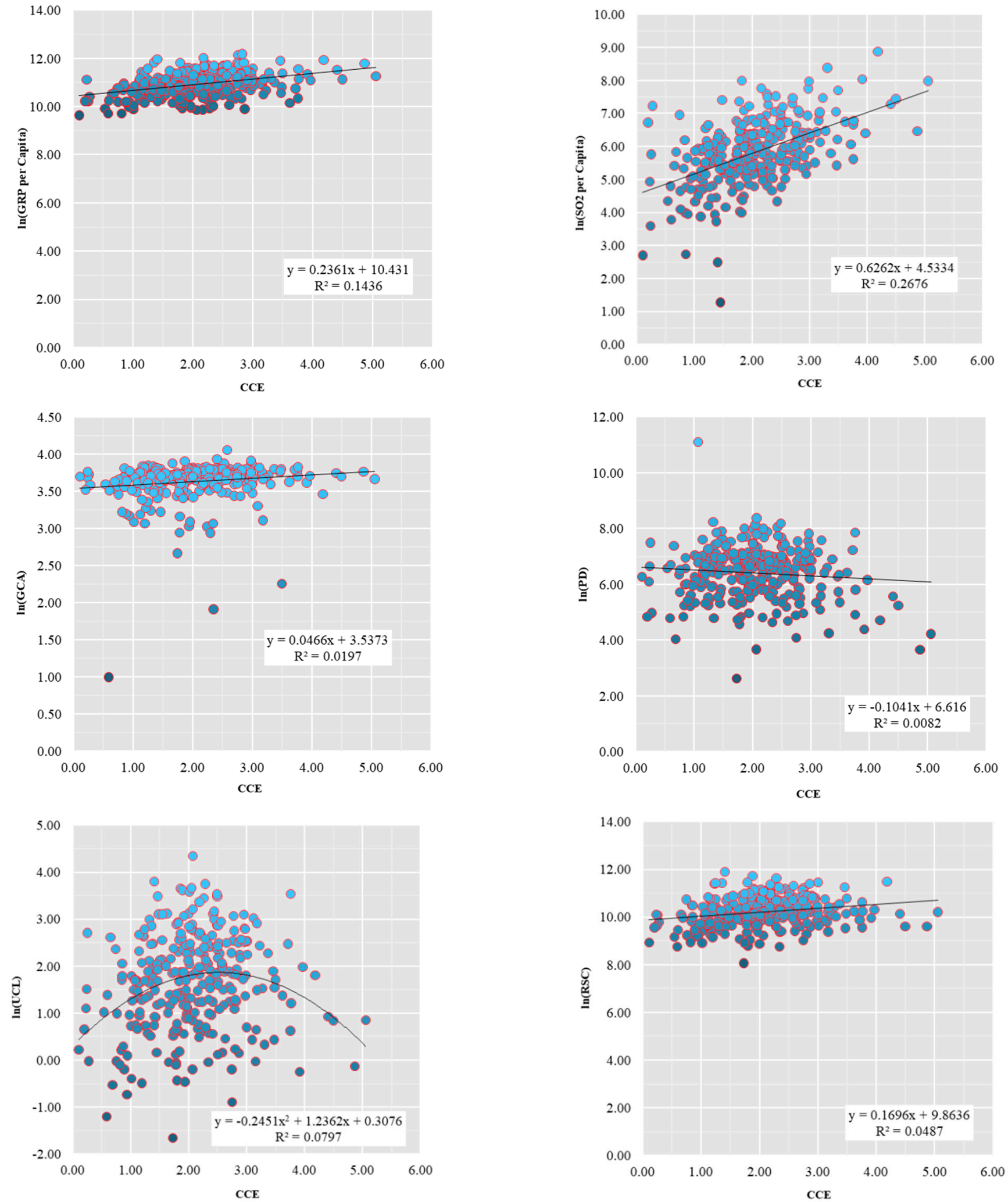

Figure 5. Cont. 

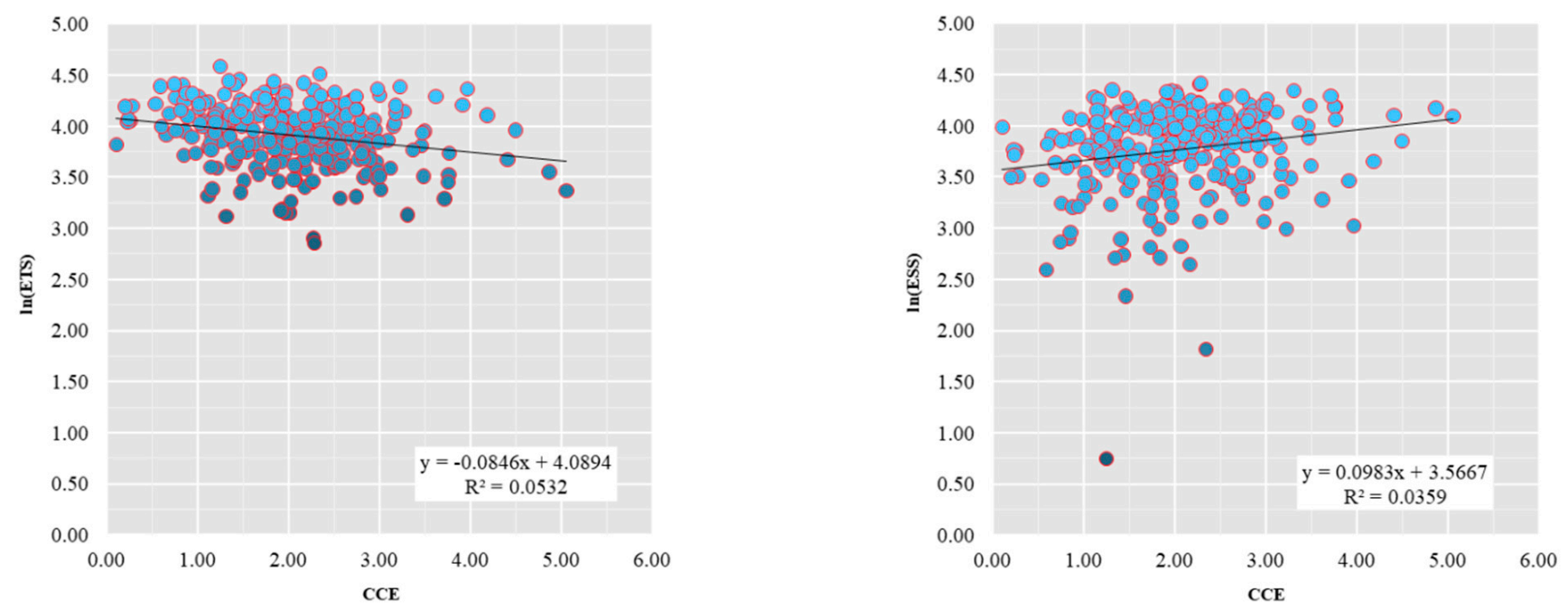

Figure 5. Correlation analysis between carbon emission variables.

The results of the Pearson correlation analysis show that (1) carbon emissions per capita (CCE) are positively correlated with GRP per capita (GRP), industrial $\mathrm{SO}_{2}$ emissions per capita $\left(\mathrm{SO}_{2}\right)$, and the proportion of employees in the secondary sector (ESS); (2) carbon emissions per capita (CCE) and population density (PD) are negatively correlated with the proportion of employees in the tertiary sector (ETS); (3) carbon emissions per capita (CCE) are (weakly) correlated with the greening coverage of built-up areas (GCA) and the proportion of urban construction land to urban area (UCL), in an inverted U-shaped curve.

In terms of the correlation between industrial structure and carbon emissions, $\mathrm{Li}$ studied the correlation between carbon emission intensity and the primary, secondary, and tertiary sectors in China, and concluded that the secondary sector is the main factor influencing regional carbon emission intensity, that the secondary sector is not the absolute factor influencing the increase of regional carbon emissions, and that the tertiary sector does not have a significant effect on the reduction of regional carbon emission intensity [80]. In terms of the correlation between demographic factors and carbon emissions, both ageing and urbanization had an inverted ' $U$ ' shaped relationship with carbon emissions [81]. In terms of the correlation between urbanization and carbon emissions, we examined the relationship between urbanization and carbon emissions in 16 emerging countries and found that the relationship between urbanization and carbon emissions in emerging developing countries was mainly positive [82]. Comparing this with our correlation analysis, we found that the influencing factor of carbon emission per capita is a multidimensional issue, not only related to economic development, development stage, and development level, but also to factors such as population density and urban construction.

\subsection{Principal Component Analysis (PCA)}

The descriptive statistics of green environment, infrastructure development, features of the built-up area, resident employment, resident savings, and consumption are shown in Table 9. Using SPSS statistical analysis software, a principal component analysis was performed on 23 independent variables, to identify their key factors (Table 10). 
Table 9. Descriptive statistics of independent variables.

\begin{tabular}{|c|c|c|c|c|c|c|}
\hline Target Layer & Indicator Layer & Max & Min & AVG & STD & Unit \\
\hline \multirow{4}{*}{$\begin{array}{c}\text { Economic } \\
\text { Development }\end{array}$} & GRP per capita & 19.58 & 1.54 & 6.27 & 3.22 & $10,000 ¥$ \\
\hline & GRP growth rate & 15.30 & -9.98 & 7.55 & 3.35 & $\%$ \\
\hline & Share of secondary sector in GRP & 74.45 & 14.33 & 46.71 & 11.05 & $\%$ \\
\hline & Share of tertiary sector in GRP & 79.65 & 22.36 & 46.70 & 10.90 & $\%$ \\
\hline \multirow{2}{*}{ Industrial level } & Number of industrial enterprises owned by 10,000 people & 59.41 & 0.40 & 9.69 & 8.59 & pcs \\
\hline & Total industrial output per capita & 156.34 & 0.94 & 27.30 & 24.24 & $10,000 ¥$ \\
\hline \multirow{3}{*}{ Pollution emission } & Industrial wastewater discharge per capita & 359.78 & 0.91 & 58.27 & 57.51 & $\mathrm{t}$ \\
\hline & $\mathrm{SO}_{2}$ per capita & 7184.07 & 3.58 & 536.87 & 684.03 & $\mathrm{~kg}$ \\
\hline & Industrial smoke (dust) emissions per capita & $16,165.72$ & 3.14 & 508.15 & 1336.21 & $\mathrm{~kg}$ \\
\hline \multirow{4}{*}{ Green Environment } & Green space per capita & 428.31 & 1.74 & 46.85 & 48.10 & $\mathrm{~m}^{2}$ \\
\hline & Parkland area per capita & 65.95 & 0.83 & 10.53 & 7.43 & $\mathrm{~m}^{2}$ \\
\hline & Greening coverage area per capita in built-up areas (GCB) & 215.67 & 0.68 & 39.05 & 23.10 & ha \\
\hline & Green covered area of built-up area (GCA) & 57.94 & 2.71 & 38.82 & 6.93 & $\%$ \\
\hline Infrastructure & Fixed asset investment per capita (FAI) & 19.96 & 0.93 & 5.73 & 3.36 & $10,000 ¥$ \\
\hline Development & Urban road area per capita (URA) & 106.27 & 1.25 & 13.19 & 9.53 & $\mathrm{~m}^{2}$ \\
\hline \multirow{2}{*}{$\begin{array}{l}\text { Features of the } \\
\text { built-up area }\end{array}$} & Population density (PD) & $65,911.00$ & 13.85 & 1068.63 & 3892.50 & person $/ \mathrm{km}^{2}$ \\
\hline & Urban construction land as proportion of urban area (UCL) & 77.32 & 0.19 & 8.40 & 9.08 & $\%$ \\
\hline \multirow{3}{*}{ Resident employment } & Number of employees in urban units with 10,000 people & $13,386.64$ & 125.56 & 2200.93 & 1488.35 & person \\
\hline & Proportion of employees in secondary sector (ESS) & 82.60 & 2.11 & 46.46 & 15.35 & $\%$ \\
\hline & Proportion of employees in tertiary sector (ETS) & 97.89 & 17.38 & 52.50 & 14.91 & $\%$ \\
\hline \multirow{2}{*}{$\begin{array}{l}\text { Resident savings and } \\
\text { consumption }\end{array}$} & RMB savings deposits per resident (SDR) & 28.17 & 1.13 & 5.86 & 3.57 & $10,000 ¥$ \\
\hline & Capita retail sales of consumers goods (RSC) & 14.60 & 0.32 & 3.32 & 2.19 & $10,000 ¥$ \\
\hline
\end{tabular}


Table 10. Total explained variance.

\begin{tabular}{ccccccc}
\hline \multirow{2}{*}{ Ingredients } & \multicolumn{3}{c}{ Initial Eigenvalue } & \multicolumn{3}{c}{ Extraction of Squares and Loading } \\
\cline { 2 - 7 } & Total & Variance(\%) & Cumulative(\%) & Total & Variance(\%) & Cumulative(\%) \\
\hline 1 & 8.83 & 38.39 & 38.39 & 8.83 & 38.39 & 38.39 \\
2 & 3.02 & 13.12 & 51.50 & 3.02 & 13.12 & 51.50 \\
3 & 2.56 & 11.13 & 62.63 & 2.56 & 11.13 & 62.63 \\
4 & 1.53 & 6.64 & 69.27 & 1.53 & 6.64 & 69.27 \\
5 & 1.35 & 5.87 & 75.14 & 1.35 & 5.87 & 75.14 \\
6 & 1.02 & 4.41 & 79.55 & 1.02 & 4.41 & 79.55 \\
\hline
\end{tabular}

Extraction method: principal component analysis.

First, a KMO test and Bartlett test were performed on the data matrix of $286 \times 23$ variables, and the results showed that the Kaiser-Meyer-Olkin (KMO) measure of sampling adequacy was 0.835 . According to the criterion of being able to perform principal component analysis with a KMO value greater than 0.8 proposed by statistician Kasier, the data matrix variables used in this study were able to perform a principal component analysis. Meanwhile, the significance level of Bartlett's sphericity test was 0.001, and the principal component analysis was significant.

Second, the explained total variance was measured. The principal component analysis method was chosen in the factor analysis, based on the eigenvalues, and variables with eigenvalues greater than 1 were extracted to give the explained total variance table. In the explained total variance table, the cumulative variance contribution of the top six components reached $79.55 \%$, which means that these six principal factors can represent $79.55 \%$ of the information of 23 variables. The six principal factors have the ability to express the information of the key factors.

Third, naming of the principal component variables. Combined with the rotated component matrix table, the main influencing factors of the six principal components were comprehensively assessed, based on the correlation coefficients in the correlation matrix. The RMB savings deposits per resident (SDR) and capita retail sales of consumer goods (RSC) in the first principal component have relatively high loadings; therefore, the first principal component can be named as 'resident savings and consumption factor'. The three variables of industrial wastewater discharge per capita, $\mathrm{SO}_{2}$ per capita, and industrial smoke (dust) emissions per capita in the second principal component have relatively high loadings; therefore, the second principal component can be named as 'pollution emission factor'. The two variables share of secondary sector in GRP and share of tertiary sector in GRP have relatively high loadings; therefore, the third principal component can be named as 'economic structure factor'. The fourth principal component, population density (PD), has a relatively high loading, so can be named as 'population density factor'. The GRP growth rate in the fifth principal component has a high loading, so it can be named as the 'economic growth factor'. The green covered area of built-up area (GCA) in the sixth principal component can be named as the 'resident employment factor' (Table 11). 
Table 11. Rotated Component Matrix.

\begin{tabular}{lcccccc}
\hline Variables & $\mathbf{1}$ & $\mathbf{2}$ & $\mathbf{3}$ & $\mathbf{4}$ & $\mathbf{5}$ & $\mathbf{6}$ \\
\hline GRP per capita & 0.77 & -0.02 & 0.30 & 0.12 & 0.27 & -0.03 \\
GRP growth rate & -0.01 & -0.16 & -0.03 & 0.05 & 0.83 & -0.07 \\
Share of secondary sector in GRP & 0.02 & 0.18 & 0.82 & -0.01 & 0.25 & 0.26 \\
Share of tertiary sector in GRP & 0.34 & -0.07 & -0.72 & 0.31 & -0.28 & -0.19 \\
Number of industrial enterprises owned by 10,000 people & 0.22 & 0.57 & 0.16 & 0.41 & 0.40 & 0.15 \\
Total industrial output per capita & 0.44 & 0.53 & 0.31 & 0.35 & 0.41 & 0.11 \\
Industrial wastewater discharge per capita & 0.21 & 0.77 & 0.09 & 0.14 & 0.14 & 0.07 \\
SO per capita & 0.13 & 0.87 & 0.04 & -0.15 & -0.19 & -0.04 \\
Industrial smoke (dust) emissions per capita & 0.09 & 0.80 & -0.03 & -0.10 & -0.20 & -0.06 \\
Green space per capita & 0.81 & 0.15 & 0.00 & 0.01 & 0.03 & 0.35 \\
Parkland area per capita & 0.78 & 0.22 & -0.02 & 0.13 & -0.03 & 0.20 \\
Greening coverage area per capita in built-up areas (GCB) & 0.81 & 0.27 & 0.06 & 0.02 & -0.07 & 0.41 \\
Green covered area of built-up area (GCA) & 0.24 & -0.04 & 0.19 & 0.17 & -0.08 & 0.84 \\
Fixed asset investment per capita (FAI) & 0.69 & 0.08 & 0.17 & 0.13 & 0.43 & -0.09 \\
Urban road area per capita (URA) & 0.75 & 0.31 & 0.05 & 0.01 & 0.06 & 0.21 \\
Built-up area per capita (BUA) & 0.84 & 0.27 & -0.08 & -0.05 & -0.07 & -0.04 \\
Population density (PD) & 0.08 & -0.05 & 0.15 & 0.90 & 0.09 & 0.11 \\
Urban construction land as proportion of urban area (UCL) & 0.48 & 0.05 & 0.12 & 0.77 & 0.02 & 0.08 \\
Number of employees in urban units with 10,000 people & 0.81 & -0.01 & 0.22 & 0.27 & -0.10 & -0.08 \\
Proportion of employees in secondary sector (ESS) & 0.15 & 0.01 & 0.84 & 0.32 & -0.11 & 0.01 \\
Proportion of employees in tertiary sector (ETS) & -0.22 & 0.02 & -0.82 & -0.22 & 0.20 & 0.08 \\
RMB savings deposits per resident (SDR) & 0.85 & 0.04 & -0.10 & 0.29 & -0.10 & -0.03 \\
Capita retail sales of consumers goods (RSC) & 0.80 & -0.03 & 0.01 & 0.44 & 0.09 & -0.03 \\
\hline
\end{tabular}

Extraction method: principal component analysis.

Finally, the scores of the six main factors were measured using SPSS software, and six factor scores for principal component analysis were obtained: factor score 1, factor score 2, factor score 3 , factor score 4 , factor score 5 , and factor score 6.

\subsection{Stepwise Regression Analysis}

A carbon emission regression model was constructed with carbon emission per capita as the dependent variable and the six variables of the main factor analysis as the independent variables.

$$
\mathrm{Y}=\beta_{0}+\alpha \text { Factor1 }+\beta \text { Factor } 2+\chi \text { Factor3 }+\delta \text { Factor } 4+j \text { Factor } 5+\varphi \text { Factor6 }+\varepsilon_{i}
$$

$\beta_{0}$ is the constant term, the coefficients $\alpha \sim \psi$ are the coefficients to be determined, the coefficients to be determined can be derived by multiple regression analysis, and $\varepsilon_{\mathrm{i}}$ is the error term.

The first to the sixth principal components are the resident savings and consumption factor, pollution emission factor, economic structure factor, population density factor, economic growth factor, and resident employment factor, respectively. We expect that the residential savings and consumption factor, pollution emission factor, population density factor, economic growth factor, and residential employment factor may all bring about an increase in carbon emissions, while the economic structure factor may bring about an increase or a decrease in carbon emissions.

The basic idea of the stepwise regression analysis method is to automatically select the most important variables from the large number of available variables and build a predictive or explanatory model for regression analysis. The independent variables are introduced one by one, and their partial regression sum of squares is tested for significance. At the same time, after each new independent variable is introduced, the old independent variables are tested one by one, and the independent variables with insignificant regression 
sums of squares are eliminated. In this way, we keep eliminating while introducing, until no new variables are introduced and no old variables are removed. The essence is to establish the 'optimal' multiple linear regression equation (Table 12). Our regression model explains the contribution of the per capita carbon emissions impact factor with an adjusted R-squared of 0.400 , meaning that the factors in the model explain $40 \%$ of the impact factor in per capita carbon emissions; leaving $60 \%$ of the impact factor as not yet included in this model.

Table 12. Models Summary.

\begin{tabular}{ccccc}
\hline Model & $\mathbf{R}$ & R-Square & Adjusted R-Square & Standard Error in Estimation \\
\hline 1 & $0.420^{\mathrm{a}}$ & 0.176 & 0.174 & 0.749 \\
2 & $0.510^{\mathrm{b}}$ & 0.260 & 0.255 & 0.711 \\
3 & $0.581^{\mathrm{c}}$ & 0.337 & 0.330 & 0.675 \\
4 & $0.612^{\mathrm{d}}$ & 0.374 & 0.366 & 0.657 \\
5 & $0.640^{\mathrm{e}}$ & 0.410 & 0.400 & 0.639 \\
\hline
\end{tabular}

a. Predictive variables: (Constant), REGR factor score 1 for analysis $1 .^{b}$. Predictive variables: (Constant), REGR factor score 1 for analysis 1 , REGR factor score 2 for analysis 1 . ${ }^{c}$. Predictive variables: (Constant), REGR factor score 1 for analysis 1, REGR factor score 2 for analysis 1, REGR factor score 5 for analysis $1 .{ }^{\mathrm{d}}$. Predictive variables: (Constant), REGR factor score 1 for analysis 1, REGR factor score 2 for analysis 1, REGR factor score 5 for analysis 1, REGR factor score 3 for analysis 1. e. Predictive variables: (Constant), REGR factor score 1 for analysis 1, REGR factor score 2 for analysis 1, REGR factor score 5 for analysis 1, REGR factor score 3 for analysis 1, REGR factor score 4 for analysis 1 .

Stepwise regression was used to screen and remove variables that cause multi-collinearity in the following steps: a simple regression is first done with the explanatory variables for each of the explanatory variables considered, and then the regression equation corresponding to the explanatory variable that contributes most to the explanatory variable is used as the basis for gradually introducing the remaining explanatory variables. After the stepwise regression is performed, so that the final explanatory variables retained in the model are both significant and free from severe multi-collinearity. The results of the stepwise regression analysis showed that factor 6 was excluded due to the problem of cointegration, and the final regression coefficients were as in Table 7.

Based on the unstandardized regression coefficients in Table 13, we constructed the carbon emission regression model.

$$
\mathrm{Y}=0.346 \text { Factor1 }+0.239 \text { Factor2 }+0.159 \text { Factor3 }-0.156 \text { Factor } 4-0.228 \text { Factor } 5+2.051
$$

Table 13. Regression coefficients ${ }^{a}$.

\begin{tabular}{|c|c|c|c|c|c|}
\hline Model & Non-Standardized Coefficients & Standard Errors & Standard Coefficients & $\mathbf{t}$ & Sig. \\
\hline (Constant) & 2.051 & 0.038 & & 54.584 & 0.000 \\
\hline Factor1 & 0.346 & 0.038 & 0.42 & 9.201 & 0.000 \\
\hline Factor2 & 0.239 & 0.038 & 0.29 & 6.347 & 0.000 \\
\hline Factor3 & 0.159 & 0.038 & 0.193 & 4.22 & 0.000 \\
\hline Factor4 & -0.156 & 0.038 & -0.189 & -4.141 & 0.000 \\
\hline Factor5 & -0.228 & 0.038 & -0.277 & -6.068 & 0.000 \\
\hline
\end{tabular}

a. Dependent variable: Capita carbon emissions.

Factor 1: resident savings and consumption showed a positive relationship with carbon emissions per capita, with a t-value of 9.201 and a $p$-value less than 0.01 , indicating that the Factor1 variable in the regression model is significant. The regression coefficient is 0.346 , and each $1 \%$ increase in residents' savings and consumption will bring a positive increase of $0.346 \%$ in per capita carbon emissions, controlling other variables as constant.

Factor 2: Pollution emission factor had a positive effect on carbon emissions per capita, with a t-value of 6.347 and a $p$-value less than 0.01 , indicating that pollution emissions can 
significantly promote carbon emissions. The regression coefficient is 0.239 , and every $1 \%$ increase in pollution emission factor will bring a positive increase of $0.239 \%$ in per capita carbon emissions, keeping other variables constant.

Factor 3: The relationship between the economic structure factor and per capita carbon emission is complex, and our study used the number of employees in the three industries to represent the economic structure factor. In the correlation analysis, the proportion of employees in the secondary sector (ESS) was positively correlated with carbon emissions per capita, while the proportion of employees in tertiary sector (ETS) was negatively correlated with carbon emissions per capita. In the regression analysis, there was a positive correlation between the economic structure factor and per capita carbon emissions, which was due to the fact that the current energy structure of China is still dominated by coal and supplemented by clean energy. Despite the Chinese government's efforts to reduce energy consumption and improve energy conservation and emission reductions, it has not yet fundamentally changed the energy structure, which is the key factor leading to the positive correlation between the economic structure factor and carbon emission per capita. The Factor3 variable in the regression model was significant, with a regression coefficient of 0.159 , indicating that every $1 \%$ adjustment in economic structure will bring a $0.159 \%$ increase in carbon emissions per capita.

Factor 4: Population density and carbon emissions per capita showed a negative relationship, with a t-value of -4.141 and a $p$-value less than 0.01 , indicating that the Factor4 variable in the regression model was significant. The regression coefficient is -0.156 , which shows that every $1 \%$ increase in population density will lead to a $0.156 \%$ decrease in per capita carbon emissions, controlling for other variables. The rapid urbanization process, the concentration of population toward towns and cities, the spatial clustering of populations, and the development of urban agglomerations mitigate carbon emissions per capita.

Factor 5: The economic growth factor and carbon emissions per capita showed a negative relationship, with a $\mathrm{t}$-value of 9.201 and a $p$-value less than 0.01 , indicating that the Factor5 variable in the regression model is significant. The regression coefficient is 0.228 , and every $1 \%$ increase in economic growth factor will bring a negative increase of $0.228 \%$ in per capita carbon emissions, keeping other variables constant.

\section{Discussion}

This study empirically analyzed the spatial heterogeneity of carbon emissions in 286 cities at prefecture level and above in China, analyzed the factors for the evolution of regional differences in carbon emissions in the four major regions of China, revealed the factors influencing carbon emissions in Chinese cities, and provided an empirical basis for the formulation of low-carbon emission reduction measures and policies in China. This study is different from those of other scholars, such as Liu and Li, who analyzed the temporal and spatial pattern of China's carbon emissions [83,84]. We conducted a spatial heterogeneity analysis of carbon emissions in 20 sectors of 286 prefecture-level-andabove cities in China, and the study was able to observe the spatio-temporal differences of carbon emissions in China from a multi-sectoral perspective. In terms of the analysis of the influencing factors of carbon emissions, $\mathrm{Xu}$ revealed the existence of an environmental Kuznets curve for carbon emissions at the provincial level in China [85], but an analysis of influencing factors is still lacking. Although scholars such as Zhao, Cai, and Zhao [86-88] analyzed the influencing factors of carbon emissions, some of their analyses were spatially scaled to Chinese provinces, while the analysis of specific factors only focused on aspects such as urbanization and industrial composition, lacking an analysis of the influence of demographic, economic, and environmental variables. Our study has taken into account these factors, which will contribute to the study of the impact mechanism of low carbon emission reductions in China. Of course, our study also has certain shortcomings, as policy factor variables are missing from our explanatory variables, due to the limited availability of data. In China, policy factors have a strong influence on economic development, social 
transformation, and low carbon emission reduction. To fill this gap, we included policy factors in the policy recommendation section.

\section{Conclusions}

Using a combination of comparative analysis, regional difference analysis, correlation analysis, principal component analysis, and stepwise regression analysis, the spatial heterogeneity of carbon emissions and its influencing factors in 286 prefecture-level-and above-cities in China were studied, and the following conclusions were drawn:

(1) In the analysis of the spatial heterogeneity of carbon emissions in 286 cities at prefectural level and above in China, the regional differences in six sectors, including urban household carbon emissions, railway carbon emissions, aviation carbon emissions, carbon emissions per unit GDP, carbon emissions per unit GDP in primary industry, and carbon emissions per unit GDP in secondary industry all widened, while the regional differences in rural household carbon emissions, agricultural carbon emissions, industrial carbon emissions, service carbon emissions, road carbon emissions carbon emissions, carbon emissions from water navigation, carbon emissions from transportation, direct carbon emissions, indirect carbon emissions, total carbon emissions, carbon emissions per capita, carbon emissions per unit of land area, carbon emissions per unit of GDP in the tertiary sector, and carbon productivity all narrowed; the regional differences narrowed in 14 sectors.

(2) In terms of the spatial heterogeneity of carbon emissions in the four major regions of China, including the northeast, eastern, central, and western regions, the intra-group differences in six sectors, including urban household carbon emissions, railway carbon emissions, aviation carbon emissions, carbon emissions per unit GDP, carbon emissions per unit GDP in the primary industry, and carbon emissions per unit GDP in the secondary industry, are significant, as shown in the northeast, eastern, central, and western regions. The within-group differences in carbon emissions of the six sectors in China are different.

(3) From 2005 to 2015, the carbon emissions of rural households in China were higher than those of urban households, and the carbon emissions of the three major sectors, namely agriculture, industry, and services, increased significantly. The carbon emissions from the four major sectors of 'iron, public, and infrastructure' are increasing at a significant rate, and carbon emissions per capita and per land area are also increasing, with indirect carbon emissions increasing at a significantly faster rate than direct carbon emissions. Although the carbon emissions of all sectors in China's 286 cities are expanding, it is surprising to see that the overall carbon emission intensity of China's 286 cities has decreased, in terms of carbon emissions per unit GDP and the average carbon emissions per unit GDP of primary, secondary and tertiary industries, which means that China has taken steps to reduce carbon emissions and put them into practice.

(4) From the results of the correlation analysis, carbon emissions per capita (CCE) are positively correlated with GRP per capita (GRP), industrial $\mathrm{SO}_{2}$ emissions per capita $\left(\mathrm{SO}_{2}\right)$, and the proportion of employees in the secondary industry (ESS). Carbon emissions per capita (CCE) and population density (PD) are negatively correlated with the proportion of workers in the tertiary sector (ETS). Carbon emission per capita (CCE) is (weakly) correlated with the green coverage of built-up areas (GCA) and the proportion of urban construction land to urban area (UCL), in an inverted U-shaped curve.

(5) In terms of the explanatory factors of carbon emissions, residential savings and consumption are positively correlated with per capita carbon emissions, and pollution emission factors are positively correlated with per capita carbon emissions, with each $1 \%$ increase in pollution emission factors bringing a $0239 \%$ positive increase in per capita carbon emissions; the regression coefficient is 0.159 , indicating that each $1 \%$ adjustment in economic structure will bring a $0.159 \%$ increase in per capita carbon emissions. Every $1 \%$ increase in population density will lead to a $0.156 \%$ negative increase in per capita carbon emissions; and every $1 \%$ increase in the economic growth factor will lead to a $0.228 \%$ negative increase in per capita carbon emissions, controlling for other variables. 


\section{Policy Suggestions}

In October 2021, the northeast region of China was the first to start limiting electricity. Subsequently, Guangdong, Anhui, Jiangsu, and Zhejiang started to restrict electricity, and some high energy-consuming enterprises restricted electricity for 10 days. The apparent reason for this is the rising price of coal; the essential reason is the lack of capacity needed for the low-carbon transition.

China's power restriction is an inevitable event, and the root problem behind the power restriction is long-term and global. The issue of coal utilization is a paradoxical problem that China has to face in the long run. According to our empirical study, the pollution emission factor has a significantly positive correlation with carbon emission per capita, and pollution emission is mostly dominated by high energy-consuming enterprises. The empirical study also showed that economic restructuring still exacerbates the increase of carbon emission per capita, indicating that a fundamental transformation of economic structure has not yet occurred. Therefore, we suggest the following:

First, strengthen the coordination of economic development and energy structure, to balance energy supply and demand, matching construction. After 2000, China's energy demand exceeded expectations, leading to a shortage of energy supply and a nationwide short supply of coal, electricity, and oil, which stimulated energy production capacity. After the 2008 financial crisis, energy supply slowed down, but the Chinese government's 'four trillion' infrastructure construction plan in the process of economic recovery stimulated building capacity and exacerbated the tight energy supply situation. In 2021, the energy supply is again tight and power supply is restricted, indicating the incongruity between China's energy supply and economic development. Therefore, properly handling the contradiction between the transformation of energy structure and the transformation of economic development is the necessary path for China to follow a sustainable development path and achieve energy self-sufficiency in the future.

Second, accelerate the construction of new infrastructure capacity to match the new energy system. The path to a low-carbon transition is important for every country, and for China, the world's largest developing country, accelerating the construction of new infrastructure to match new energy construction is a hardware condition and a technical condition for guaranteeing the transformation of China's energy structure. For example, the renovation of the distribution grid could significantly reduce energy consumption. It is recommended to strengthen the coordination and coupling of energy and infrastructure construction, accelerate the synergistic use of media and new energy, etc., build a supply system with complementary energy sources, and promote the construction of a support network system for the new energy supply system.

Third, promote green development and a green and low-carbon lifestyle. Green development is a method of economic growth and social development that aims at efficiency, harmony, and sustainability. Green lifestyle aims to make green consumption, green travel, and green living become part of people's conscious actions by encouraging residents to use green products and encouraging people to participate in green voluntary services, as well as guiding people to establish the concept of green growth and sharing together. The former focuses on the comprehensive, coordinated, and sustainable development of the economy, society, and environment at a macro level, while the latter focuses on the transformation of residents' personal lifestyles at a micro level, focusing on low-carbon, energy-saving, and environmental protection. Green development means promoting the transformation of the city, from the old sloppy urban economic growth mode, to an intensive economic growth mode, while green lifestyle means improving the residents' concept of environmental protection, focusing on the recycling of resources in life, using public transport as the main mode of travel, strengthening the conscious process of waste separation, and saving water and electricity and other daily resources.

Author Contributions: Writing-C.L.; Methodology-H.L.; Conceptualization-X.Q. All authors have read and agreed to the published version of the manuscript. 
Funding: Program for Innovative Research Team of Huainan Normal University (No. XJTD202001); Educational Commission of University Humanities and Social Sciences of Anhui Province (No.SK2018A0502); China Postdoctoral Science Foundation (2020M671045); Project of Philosophy and Social Science of Shanghai (2020EJB007); Key Projects of Soft Science Research of Shanghai (21692193400).

Institutional Review Board Statement: This research did not involve humans.

Informed Consent Statement: Informed consent was obtained from all subjects involved in the study.

Data Availability Statement: China City Greenhouse Gases Emission Dataset (2005) and China City Greenhouse Gases Emission Dataset (2015), China Urban Statistical Yearbook 2016 and China Urban Construction Statistical Yearbook 2015.

Conflicts of Interest: The authors declare no conflict of interest.

\section{Abbreviations}

The following abbreviations are used in this manuscript: CCE: Capita Carbon Emissions; TCE: Total Carbon Emissions; $\mathrm{SO}_{2}$ per Capita: Capita Volume of Sulphur Dioxide Emission; GCA: Green Covered Area as Proportion of Completed Area; PD: Population Density; UCL: Urban Built-Up Area as Proportion of Urban Area; ESS: Proportion of Employees in the Secondary Sector; ETS: Proportion of Employees in the Tertiary Sector; RSC: Capita Retail Sales of Consumer Goods.

\section{References}

1. Wang, S.J.; Xie, Z.H.; Wang, Z.H. The spatiotemporal pattern evolution and influencing factors of $\mathrm{CO}_{2}$ emissions at the county level of China. Acta Geographica Sinica 2021, 76, 3103-3118.

2. Fan, F.; Lian, H.; Liu, X. Can environmental regulation promote urban green innovation Efficiency? An empirical study based on Chinese cities. J. Clean. Prod. 2020, 287, 125060. [CrossRef]

3. Fan, F.; Zhang, X.R. Transformation effect of resource-based cities based on PSM-DID model: An empirical analysis from China. Environ. Impact Assess. Rev. 2021, 91, 106648. [CrossRef]

4. Ke, H.Q.; Dai, S.Z. Does innovation efficiency inhibit the ecological footprint? An empirical study of China's provincial regions. Technol. Anal. Strateg. Manag. 2021, 33, 1959910. [CrossRef]

5. Wang, S.; Wang, X.L.; Lu, F. The impact of collaborative innovation on ecological efficiency-empirical research based on China's regions. Technol. Anal. Strateg. Manag. 2020, 32, 242-256. [CrossRef]

6. Liu, S.; Fan, F.; Zhang, J.Q. Are Small Cities More Environmentally Friendly? An Empirical Study from China. Int. J. Environ. Res. Public Health 2019, 16, 727. [CrossRef]

7. Ke, H.Q.; Dai, S.Z.; Yu, H.C. Spatial effect of innovation efficiency on ecological footprint: City-level empirical evidence from China. Environ. Technol. Innov. 2021, 22, 101536. [CrossRef]

8. Wang, S.; Jia, M.; Zhou, Y. Impacts of changing urban form on ecological efficiency in China: A comparison between urban agglomerations and administrative areas. J. Environ. Plan. Manag. 2019, 8, 1-23. [CrossRef]

9. Ke, H.Q.; Yang, W.Y.; Liu, X.Y. Does Innovation Efficiency Suppress the Ecological Footprint? Empirical Evidence from 280 Chinese Cities. Int. J. Environ. Res. Public Health 2020, 17, 6826. [CrossRef]

10. Zhang, J.Q.; Wang, S.; Yang, P.L. Analysis of Scale Factors on China's Sustainable Development Efficiency Based on Three-Stage DEA and a Double Threshold Test. Sustainability 2020, 12, 2225. [CrossRef]

11. China City Greenhouse Gas Working Group. China City Greenhouse Gases Emission Dataset; China Environment Publishing Group: Beijing, China, 2019.

12. Wang, S.J.; Su, Y.X.; Zhao, Y.B. Regional inequality, spatial spillover effects and influencing factors of China's city-level energyrelated carbon emissions. Acta Geographica Sinica 2018, 73, 414-428.

13. Li, J.K.; Ma, J.J.; Wei, W. Study on regional differences of energy carbon emission efficiency in eight economic areas of China. J. Quant. Tech. Econ. 2020, 6, 109-129.

14. Qiu, L.X.; Xu, H.T. Analysis of Spatial-Temporal Evolution and Impact Factors of Urban Agglomerations Carbon Emissions in China. Soft Sci. 2018, 32, 109-113.

15. Wang, S.J.; Gao, S.; Huang, Y.Y.; Shi, C.Y. Spatio-temporal evolution and trend prediction of urban carbon emission performance in China based on super-efficiency SBM model. Acta Geographica Sinica 2020, 75, 1316-1330.

16. Wu, Z.L.; Wang, D.; Su, Y.T. Study on Spatial-temporal Variation and Influencing Factors of Urban Carbon Emissions in Guangdong Province based on EDGAR Data. Areal Res. Dev. 2020, 39, 127-132.

17. Xu, G.Q.; Cai, Z.; Feng, S.W. Spatial and Temporal Differences and Influencing Factors of Carbon Emissions Based on the Analysis of the Two-stage LMDI Model-An Empirical Study on Jiangsu Province. Soft Sci. 2021, 35, 107-113. 
18. Xia, S.Y.; Zhao, Y.; Xu, X.; Wen, Q.; Cui, P.P.; Tang, W.M. Regional Inequality, Spatial-Temporal Pattern and Dynamic Evolution of Carbon Emission Intensity from Agriculture in China in the Period of 1997-2016. Resour. Environ. Yangtze Basin 2020, $29,596-608$.

19. He, Q.Y.; Dai, X.W. Phase characteristics and regional differences in agriculture carbon emissions in China. Resour. Sci. 2016, 38, 1780-1790.

20. Shi, J.H.; Dai, X.W. Spatial dynamics of agricultural embodied carbon emissions in provinces of china and the related diving factors. Chin. J. Agric. Resour. Reg. Plan. 2020, 41, 169-179.

21. Wang, K.; Tang, X.H.; Gan, C.; Liu, H.L. Temporal-spatial evolution and influencing factors of carbon emission intensity of China's service industry. China Popul. Resour. Environ. 2021, 31, $23-31$.

22. Wang, X.; Zhang, L.J.; Qin, C.Y.; Zhang, J.F. Spatiotemporal changes of carbon emissions in high-carbon manufacturing industry in China and driving factors. Resour. Sci. 2020, 42, 323-333. [CrossRef]

23. Liu, L.N.; Qu, J.S.; Huang, Y.S.; Wang, L.; Zeng, J.J. Analyze on the spatial-temporal pattern and influence factors of China's per Capita Household carbon emissions. J. Nat. Resour. 2016, 31, 1364-1377.

24. Yuan, C.W.; Zhang, S.; Jiao, P.; Wu, D.Y. Temporal and spatial variation and influencing factors research on total factor efficiency for transportation carbon emissions in China. Resour. Sci. 2017, 39, 687-697.

25. Cao, Z.H.; Hao, J.M.; Xing, H.P. Spatial-temporal change of Chinese resident food consumption carbon emissions and its driving mechanism. Prog. Geogr. 2020, 39, 91-99. [CrossRef]

26. Schipper, L. Carbon emissions from manufacturing energy use in 13 IEA countries. Energy Policy 2001, 29, 667-688. [CrossRef]

27. Casler, S.D. Carbon dioxide emissions in the U.S. economy. Environ. Resour. Econ. 1998, 11, 349-363. [CrossRef]

28. Chang, Y.F.; Lin, S.J. Structural decomposition of industrial $\mathrm{CO}_{2}$ emission in Taiwan. Energy Policy 1998, 26, 5-12. [CrossRef]

29. Guo, C.X. An analysis of the increase of $\mathrm{CO}_{2}$ Emission in China-Based on SDA technique. China Ind. Econ. 2010, 12, 47-56.

30. Yu, Y.; Chen, C. Spatial and temporal characteristics of net emission of carbon dioxide in China. Sci. Geogr. Sin. 2013, 33, 1173-1179.

31. Wang, S.; Fang, C.; Wang, Y. Spatiotemporal variations of energy related $\mathrm{CO}_{2}$ emissions in China and its influencing factors: An empirical analysis based on provincial panel data. Renew. Sustain. Energy Rev. 2016, 55, 505-515. [CrossRef]

32. Yang, Q.; Liu, H. Regional differences and convergence of carbon intensity distribution in China: Based on an empirical study of provincial data 1995-2009. Contemp. Financ. Econ. 2012, 1, 87-98.

33. Wang, Z.; Du, Y. Spatial-temporal differences and influencing factors of carbon emission efficiency in Hunan Province based on SBM-DEA model. Sci. Geogr. Sin. 2019, 39, 797-806.

34. Zhao, Y.; Huang, X.; Zhong, T. Spatial pattern evolution of carbon emission intensity from energy consumption in China. Chin. J. Environ. Sci. 2011, 32, 3145-3152.

35. Zhou, J.; Wang, Y.; Liu, X.; Shi, X.C.; Cai, C.M. Spatial temporal differences of carbon emissions and carbon compensation in China based on land use change. Sci. Geogr. Sin. 2019, 39, 1955-1961.

36. Cheng, Y.Q.; Wang, Z.Y.; Ye, X.Y.; Wei, Y.H. Spatiotemporal dynamics of carbon intensity from energy consumption in China. J. Geogr. Sci. 2014, 24, 631-650. [CrossRef]

37. Guan, Y.; Kang, L.; Shao, C.; Wang, P.; Ju, M. Measuring county-level heterogeneity of $\mathrm{CO}_{2}$ emissions attributed to energy consumption: A case study in Ningxia Hui Autonomous Region, China. J. Clean. Prod. 2017, 142, 3471-3481. [CrossRef]

38. Cai, B.; Zhang, L. Urban $\mathrm{CO}_{2}$ emissions in China: Spatial boundary and performance comparison. Energy Policy 2014, 66, 557-567. [CrossRef]

39. Wang, K.; Zhang, S.; Gan, C.; Yang, Y.P.; Liu, H.L. Spatial network structure of carbon emission efficiency of tourism industry and its effects in China. Sci. Geogr. Sin. 2020, 40, 344-353.

40. Liu, X.; Guo, R.; Zhang, Y.; Zhang, D.; Wang, Z.; Gao, C.; Xie, J. Nonparametric estimation and empirical analysis of spatial dependence structure of provincial carbon emissions in China. China Popul. Resour. Environ. 2019, 29, 40-51.

41. Wang, F.; Wu, L.; Yang, C. Driving factors for growth of carbon dioxide emissions during economic development in China. Econ. Res. J. 2010, 45, 123-136.

42. Liu, X.; Gao, C.; Zhang, Y.; Zhang, D.S.; Xie, J.N.; Song, Y.; Wang, Z.Q. Spatial dependence pattern of carbon emission intensity in China 's provinces and spatial heterogeneity of its influencing factors. Sci. Geogr. Sin. 2018, 38, 681-690.

43. Du, H.; Wei, W.; Zhang, X.Y.; Ji, X. Spatio-temporal evolution and influencing factors of energy-related carbon emissions in the Yellow River Basin: Based on the DMSP/OLS and NPP/VIIRS nighttime light data. Geogr. Res. 2021, 40, $2051-2065$.

44. Niu, Y.; Zhao, X.; Hu, Y. Spatial variation of carbon emissions from county land use in Chang-Zhu-Tan area based on NPP-VIIRS night light. Acta Sci. Circumstantiae 2021, 41, 3847-3856.

45. Huang, R.; Wang, Z.; Ding, G.; Gong, Y.R.; Liu, C.X. Trend prediction and analysis of influencing factors of carbon emissions from energy consumption in Jiangsu province based on STIRPAT model. Geogr. Res. 2016, 35, 781-789.

46. Sun, J.W.; Zhao, R.Q.; Huang, X.; Chen, Z.G. Research on carbon emission estimation and factor decomposition of China from 1995 to 2005. J. Nat. Resour. 2010, 25, 1284-1295.

47. Liu, Y.; Jin, S.T. Temporal and spatial evolution characteristics and influencing factors of energy consumption carbon emissions in six provinces of Central China. Econ. Geogr. 2019, 39, 182-191.

48. Padilla, E.; Serrano, A. Inequality in $\mathrm{CO}_{2}$ emissions across countries and its relationship with income inequality: A distributive approach. Energy Policy 2006, 34, 1762-1772. [CrossRef]

49. Heilmt, W.Q.T. Inequality in $\mathrm{CO}_{2}$ emissions between poor and rich countries. J. Environ. Dev. 1997, 6, 426-452. 
50. Poumanyvong, P.; Kaneko, S. Does urbanization lead to less energy use and lower $\mathrm{CO}_{2}$ emissions? A cross-country analysis. Ecol. Econ. 2010, 70, 434-444. [CrossRef]

51. Salahuddin, M.; Alamk, O. The effects of Internet usage and economic growth on $\mathrm{CO}_{2}$ emissions in OECD countries: A panel investigation. Renew. Sustain. Energy Rev. 2016, 62, 1226-1235. [CrossRef]

52. Shao, Z.; Lin, S.; Wang, B. Impact of economic growth pattern of the six provinces of central China on regional carbon emission: Based on the Tapio model and lag instrumental variable analysis of panel data. China Popul. Resour. Environ. 2015, $25,59-66$.

53. Hu, H. Distribution of China's population. Acta Geogr. Sin. 1935, 2, 33-74.

54. Chen, D.; Zhang, Y.; Yao, Y.; Hong, Y.; Tu, W. Exploring the spatial differentiation of urbanization on two sides of the Hu Huanyong Line-based on nighttime light data and cellular automata. Appl. Geogr. 2019, 112, 102081. [CrossRef]

55. Pedro, C.; Pedro, F. The Young Person's Guide to the Theil Index: Suggesting Intuitive Interpretations and Exploring Analytical Applications [J]. UTIP Working Paper No. 14. 2000. Available online: https://ssrn.com/abstract=228703 (accessed on 14 December 2021).

56. Fan, F.; Du, D.B. The Measure and the Characteristics of Temporal-spatial Evolution of China Science and Technology Resource Allocation Efficiency. J. Geogr. Sci. 2014, 24, 492-508. [CrossRef]

57. Fan, F.; Zhang, X.R.; Yang, W.Y. Spatiotemporal Evolution of China's ports in the International Container Transport Network under Upgraded Industrial Structure. Transp. J. 2021, 60, 43-69. [CrossRef]

58. Sun, C.Z.; Yan, X.D.; Zhao, L.S. Coupling efficiency measurement and spatial correlation characteristic of water-energy-food nexus in China. Resour. Conserv. Recycl. 2021, 164, 105151. [CrossRef]

59. Zhu, Q.Y.; Sun, C.Z.; Zhao, L.S. Effect of the marine system on the pressure of the food-energy-water nexus in the coastal regions of China. J. Clean. Prod. 2021, 319, 1-12. [CrossRef]

60. Fan, B.N.; Lan, Z.Y. Public Management Research and Quantitative Analysis Methods; Science Press: Beijing, China, 2011.

61. Wang, X.L.; Wang, L.; Wang, S. Marketisation as a channel of international technology diffusion and green total factor productivity: Research on the spillover effect from China's first-tier cities. Technol. Anal. Strateg. Manag. 2021, 33, 491-504. [CrossRef]

62. Fan, F.; Lian, H.; Wang, S. Can regional collaborative innovation improve innovation efficiency? An empirical study of Chinese cities. Growth Chang. 2020, 51, 440-463. [CrossRef]

63. Wang, S.; Zhang, J.Q. The symbiosis of scientific and technological innovation efficiency and economic efficiency in China-An analysis based on data envelopment analysis and logistic model. Technol. Anal. Strateg. Manag. 2019, 31, 67-80. [CrossRef]

64. Zhang, J.Q.; Chen, T.T. Empirical Research on Time-Varying Characteristics and Efficiency of the Chinese Economy and Monetary Policy: Evidence from the MI-TVP-VAR Model. Appl. Econ. 2018, 50, 3596-3613. [CrossRef]

65. Yu, H.C.; Liu, Y.; Liu, C.L. Spatiotemporal Variation and Inequality in China's Economic Resilience across Cities and Urban Agglomerations. Sustainability 2018, 10, 4754. [CrossRef]

66. Wu, S. SPSS Practical and Statistical Thinking; Tsinghua University Press: Beijing, China, 2018.

67. Yu, H.C.; Zhang, J.Q.; Zhang, M.Q. Cross-national knowledge transfer, absorptive capacity, and total factor productivity: The intermediary effect test of international technology spillover. Technol. Anal. Strateg. Manag. 2021, 33, 1915476. [CrossRef]

68. Wang, S.; Wang, J.; Wei, C.; Wang, X.L.; Fan, F. Collaborative innovation efficiency: From within cities to between cities-Empirical analysis based on innovative cities in China. Growth Change 2021, 52, 1330-1360. [CrossRef]

69. Wang, Z.W.; Zong, Y.X.; Dan, Y.W.; Jiang, S.J. Country risk and international trade: Evidence from the China-B \& R countries. Appl. Econ. Lett. 2021, 28, 1784-1788.

70. Xiao, Z.L.; Du, X.Y. Convergence in China's high-tech industry development performance: A spatial panel model. Appl. Econ. 2017, 49, 5296-5308.

71. Fan, F.; Zhang, K.K.; Dai, S.Z. Decoupling analysis and rebound effect between China's urban innovation capability and resource consumption. Technol. Anal. Strateg. Manag. 2021, 33, 1979204. [CrossRef]

72. Fan, F.; Dai, S.Z.; Zhang, K.K. Innovation agglomeration and urban hierarchy: Evidence from Chinese cities. Appl. Econ. 2021, 53, 6300-6318. [CrossRef]

73. Liu, N.; Fan, F. Threshold effect of international technology spillovers on China's regional economic growth. Technol. Anal. Strateg. Manag. 2020, 32, 923-935. [CrossRef]

74. Fan, F.; Cao, D.; Ma, N. Is Improvement of Innovation Efficiency Conducive to Haze Governance? Empirical Evidence from 283 Chinese Cities. Int. J. Environ. Res. Public Health 2020, 17, 6095. [CrossRef]

75. Yang, W.Y.; Fan, F.; Wang, X.L. Knowledge innovation network externalities in the Guangdong-Hong Kong-Macao Greater Bay Area: Borrowing size or agglomeration shadow? Technol. Anal. Strateg. Manag. 2021, 33, 1940922. [CrossRef]

76. Xie, J.; Sun, Q.; Wang, S.H.; Li, X.P. Does Environmental Regulation Affect Export Quality? Theory and Evidence from China. Int. J. Environ. Res. Public Health 2020, 17, 8237. [CrossRef] [PubMed]

77. China Urban Greenhouse Gas Working Group. China City Greenhouse Gases Emission Dataset (2005); China Environmental Science Press: Beijing, China, 2018.

78. Department of Urban Socio-Economic Survey; National Bureau of Statistics; People's Republic of China. China Urban Statistical Yearbook 2016; China Statistics Press: Beijing, China, 2016.

79. Ministry of Housing and Urban-Rural Development of the People's Republic of China. China Urban Construction Statistical Yearbook 2015; China Planning Press: Beijing, China, 2016.

80. Li, J.; Zhou, H. Correlation Analysis of Carbon Emission Intensity and Industrial Structure in China. China Popul. Resour. Environ. 2012, 22, 7-14. 
81. Li, F.; Aging, Y. Urbanization and Carbon Emissions: Based on China's Provincial Dynamic Panel 1995-2012. Popul. Econ. 2015, 4, 9-18.

82. Wan, Y.Y. Urbanization and carbon emissions: A test based on a heterogeneous panel model. Inn. Mong. Soc. Sci. 2014, 35, 104-108.

83. Liu, H.; Shao, M.; Ji, Y. The spatial pattern and distribution dynamic evolution of carbon emissions in China: Empirical study based on county carbon emission data. Sci. Geogr. Sin. 2021, 41, 1917-1924.

84. Li, J.B.; Huang, X.J.; Meng, H.; Zhou, Y.; Xu, G.L.; Wu, C.Y. Analysis of Cumulative Target Completion Rate of Carbon Intensity in China During the Period of "Twelfth Five-Year". Resour. Environ. Yangtze Basin 2018, 27, 1655-1664.

85. Xu, G.Y.; Song, D.Y. An Empirical Study of the Environmental Kuznets Curve for China's Carbon Emissions-Based on Provincial Panel Data. China Ind. Econ. 2010, 5, 37-47.

86. Zhao, Q.Z.; Yan, Q.Y.; Zhao, H.R. Research on Spatial Characteristics and Influencing Factors of Provincial Carbon Emissions in China. J. Beijing Inst. Technol. (Soc. Sci. Ed.) 2018, 20, 9-16.

87. Cai, B.F.; Zhao, N.; Feng, K. Study on Driving forces and Underlying Factors of Urban Carbon Dioxide Emissions. China Popul. Resour. Environ. 2013, 23, 14-20.

88. Zhao, G.M.; Zhao, G.Q.; Chen, L.Z. Research on spatial and temporal evolution of carbon emission intensity and its transition mechanism in China. China Popul. Resour. Environ. 2017, 27, 84-93. 